Rhode Island College

Digital Commons @ RIC

$1-1-2014$

\title{
The DNP: A Descriptive Study of Student Experiences and Factors Contributing to Pursuing this Degree
}

Daniel J. Neilson

Rhode Island College

Follow this and additional works at: https://digitalcommons.ric.edu/etd

Part of the Other Nursing Commons

\section{Recommended Citation}

Neilson, Daniel J., "The DNP: A Descriptive Study of Student Experiences and Factors Contributing to Pursuing this Degree" (2014). Master's Theses, Dissertations, Graduate Research and Major Papers Overview. 243.

https://digitalcommons.ric.edu/etd/243

This Major Paper is brought to you for free and open access by the Master's Theses, Dissertations, Graduate Research and Major Papers at Digital Commons @ RIC. It has been accepted for inclusion in Master's Theses, Dissertations, Graduate Research and Major Papers Overview by an authorized administrator of Digital Commons @ RIC. For more information, please contact digitalcommons@ric.edu. 


\title{
THE DNP: A DESCRIPTIVE STUDY OF STUDENT EXPERIENCES AND
}

FACTORS CONTRIBUTING TO PURSUING THIS DEGREE

\author{
by \\ Daniel Neilson \\ A Major Paper Submitted in Partial Fulfillment \\ of the Requirements for the Degree of \\ Master of Science in Nursing \\ in \\ The School of Nursing \\ Rhode Island College \\ 2014
}




\begin{abstract}
Since 2004 discourse pertaining to a terminal clinical degree in nursing has increased nationally, however few articles were found that discussed why advanced practice registered nurses (APRNs) were choosing to pursue this degree, and their lived experiences while doing so. This descriptive, qualitative research study aimed to identify contributing factors in the decision to pursue the DNP degree, and to explore the experiences of DNP student experiences. Rogers' theory of diffusion of innovations (2003) guided the study. Snowball recruitment led to seven participants from who data was collected using email conversations. Five major themes were identified: (1) personal development, (2) achieving personal goals, (3) professional advancement, (4) program attibutes and (5) relationship with others. Implications exist for the nurse contemplating this degree, for faculty who educate APRNs, and for program directors as they structure learning environments and recruit new enrollees. Recommendations include the clarification of the DNP role in the delivery of healthcare services, to identify why so few of the respondents intend to use this degree in clinical practice, and for future research into how online nursing programs can use technology to effectively teach DNPs.
\end{abstract}




\section{Table of Contents}

Table of Contents...........................................

Statement of Purpose/Background.....................................1

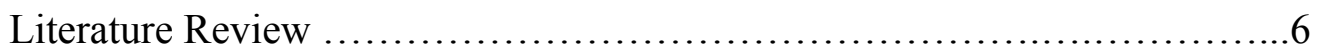

Theoretical Framework ..............................................25

Method.......................................................... 31

Results......................................................40

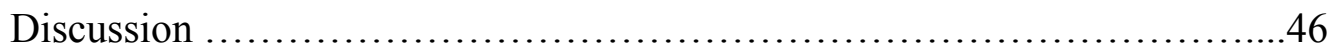

Summary and Conclusions........................................65

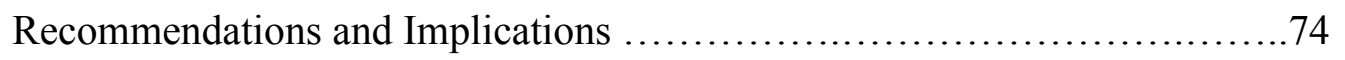

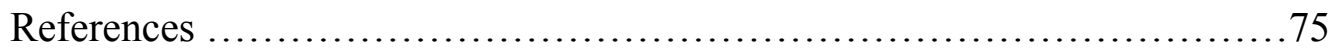




\section{Pursuing the DNP: A Descriptive Study of Student Experiences}

As the role of the advanced practice registered nurse (APRN) continues to evolve, focus on the doctorate of nursing practice (DNP) has become exceedingly prominent and a point of professional debate. Discussions regarding educational requirements in nursing are not new; discussion around the undergraduate educational requirement level for entry to practice has been prevalent for decades (ANA, 2013; Bellini \& Cusson, 2012; Hader, 2011). More recently, the focus of professional discourse has transitioned to the advanced practice degree and converged on the role and contributions of the APRN as a nurse-leader in today's complex healthcare system.

In 2004, the American Association of Colleges of Nursing (AACN) released the Position Statement On The Practice Doctorate In Nursing, in which the DNP was recommended to be, by 2015 , the terminal practice degree and educational requirement for nurses seeking entry to advanced practice. This degree was to provide nurses with the skills and specialized knowledge to be expert clinicians in the expanding and evolving healthcare system (AACN, 2006). Increasingly since this release, members of the nursing profession have discussed and disputed this degree and goal, evaluating the timing, need, and emerging issues surrounding this educational recommendation (Chase \& Pruitt, 2006; Meleis \& Dracup, 2005; Roberts \& Miller, 2009).

Concurrent to the implementation of this degree, the Institute of Medicine's publication The Future of Nursing: Leading Change, Advancing Health (IOM, 2010), identified a need for APRNs to practice to the full extent of their education, to be full 
partners with other disciplines, and to achieve higher levels of education (IOM, 2010). This vision also emphasized nurses as the primary drivers of wellness, health promotion, and disease prevention in a healthcare system that increased access to quality care for all individuals throughout society (IOM, 2010). The timing appeared appropriate for advanced practice nurses to develop and augment their presence as leaders in today's healthcare system, while fulfilling both the IOM's and AACN's seemingly parallel recommendations.

\section{Background}

Nursing practice doctorates are not new; as early as the 1970's doctoral degrees were developed within nursing programs that took divergent paths from traditional $\mathrm{PhDs}$ (AACN, 2006; Dennison, Payne \& Ferrell, 2012). These degrees (the doctor of nursing science [DNSc], the nursing doctorate [ND], the doctor of science in nursing [DSN]), were originally intended to have a clinical focus; curricula emphasized professional issues and clinical practical skills (AACN, 2006; Dennison et al., 2012). Early doctoral degrees were also developed in an effort to provide parity with other disciplines and the ND was designed to be similar to the doctor of medicine (Dennison et al., 2012). More recently, with the reconfiguring of existing curricula by the National Organization of Nurse Practitioner Faculty (NONPF), the DNP has become a relevant option for APRNs desiring a doctoral degree with an emphasis on practice excellence and delivery of care, complementary to the research and knowledge-based $\mathrm{PhD}$ (Edwardson, 2010), and filling the gap that was not adequately addressed by the DNSc, ND and DSN initiatives. 
Recognizing the exceedingly overburdened curriculum already present at the master's level, this degree was intended to be more commensurate with the credit and clinical hour requirements of advance practice programs (AACN, 2006). As delineated in the AACN's Essentials Of Doctoral Education For Advanced Nurses (2006), the curricula developed was to build upon the current master's content and further prepare nurse experts in areas of healthcare, leadership, teaching, health policy, politics, and delivery of services. The DNP curriculum differs in goals and competencies from the researchfocused $\mathrm{PhD}$ degree, preparing experts in the utilization of nursing research and in specialized advance nursing practice (AACN, 2006). As cited in Bourner, Bowden and Laing (2001), the practice doctorate was designed to develop 'researching professionals' and not 'professional researchers', as with the $\mathrm{PhD}$.

Currently the majority of advanced practice registered nurses are prepared at the master's degree level; therefore, this DNP recommendation has the potential to affect a large percentage of practicing APRNs and nurse educators. While debate and discussion continue to surround this degree, enrollment into DNP programs nationally continues to grow rapidly (AACN, 2014; Kirschling, 2013) and new graduates are entering the workforce and beginning to add their contributions. The number of schools offering this doctoral degree has grown exponentially, with more than 240 programs currently established and nearly 60 more in development (AACN, 2014; Kirschling, 2013).

In the early period of nursing doctoral degrees, graduates of practice doctorates in nursing were more often faculty members in universities and colleges with roles that had 
yet to be truly differentiated from those of $\mathrm{PhD}$ prepared educators (McEwen \& Betchel, 2000). It is perhaps for this reason that most articles, discussions, and debates surrounding the DNP have historically been within the academic and organizational venues and to some extent removed from the practicing APRN and the bedside. A recent literature review of over 90 DNP-related articles found the major themes of this ongoing dialogue to be: trends in healthcare education; the nursing faculty shortage; DNP curriculum; aspects of nursing as a profession, and the DNP's impact on patient care. It appears that the focus of the literature remains heavily centered on academic and faculty interests (Lewis, Welliver, \& Leach, 2012).

A limited number of studies written by, pertaining to, or discussing the experiences of DNP students were located. A minimal number of studies exist that describe the experiences, goals, and reflections of actual DNP students in their pursuit of this practice doctorate. As programs develop and students enroll, an opportunity exists to identify the factors that affect the decision-making process that leads to pursuing this degree, to identify the challenges and facilitators for this personal and professional endeavor, and to describe the experiences of APRNs who desire to continue their education in this innovative track.

The purpose of this descriptive study was to describe the experiences of an aggregate of current APRNs who have chosen to pursue the DNP degree, and the personal or professional reasons they decided to do so. The aim was to enhance the knowledge base surrounding this topic and to provide fresh insight for those considering 
this degree. The relevance of learning first hand experiences of DNP students may also provide nurse educators with information of interest as programs continue to strive to recruit new students and to tailor the curriculums to their needs.

Roger's theory of diffusion of innovations was selected to provide a theoretical framework for the study. This theory provided context to guide a discussion highlighting the participants' adoption of this new professional degree as well as specific factors that motivated them in the furthering of their education. 


\section{Literature Review}

The literature pertaining to advanced practice nursing degrees is extensive and has been prevalent for decades. The inundation of articles, observations, reports, and comments that followed the release of the American Association of Colleges of Nursing (AACN) 2004 Position Statement On The Practice Doctorate In Nursing, revealed a resurgence of interest in the practice doctorate. These passionate and sometimes lively discussions demonstrated the profession's enthusiasm to debate issues and share differing perspectives concerning this terminal degree. Online resources, databases, and printed publications have been consistently enriched with contributions from authors representing professional organizations, regulatory boards, educational programs, researchers, and individual editorial opinion pieces.

For this study, literature was collected over a period of seven months using the PUBMED, CINAHL Plus, and OVID databases; the last four decades of literature were reviewed with closer examination of the last 10 years. Keywords included doctorate of nursing practice, advance nursing practice, practice doctorate, doctoral nursing student, and doctoral student experience. Databases were compared for overlap and the most frequently cited and referenced primary pieces were retrieved.

Another relevant bibliography of DNP-related writings was found on the independent "Doctors of Nursing Practice" website. Described as being created by a group of APRNs whose aim is to "enhance the profession and the doctor of nursing practice degree to improve health care outcomes" (www.doctorsofnursingpractice.org), 
the website has compiled a free set of over 150 DNP-related articles. Although no synthesis or analysis was found therein, it provided substantial supplementation to the database searches.

The number of articles reviewed was narrowed down by selecting those pertaining to DNP-specific content such as position statements and fact sheets, the history of doctoral degrees in nursing, and doctoral student experiences. Articles were also compartmentalized into three time segments: pre-2002; 2002-2008 and 2008-current, due to the distinct nature and content of each period's writings. For instance, the explosion of material in the period during and immediately following the AACN's task force in 2002, and subsequent release in 2004, had a relatively speculative nature regarding the DNP that was seldom present in articles dating prior to 2002. Then, as educational programs were developed and the DNP became more prevalent, a more retrospective and balanced undertone permeated the literature with less controversy and more collegiality. The extensive collection of editorials debating the "burden versus the benefit" of the DNP (Smith, 2006) was also reviewed as they provided insight into DNP-related issues, spanning both the practicing and academic arenas.

As the abundance of literature concerning these topics is vast, meta-analyses and syntheses were first sought in order to identify the most prevalent themes and issues. One example of such was Lewis' dissertation (2011), which examined DNP-related literature for relationships between the sentiment expressed by the authors and their respective credentials. He described three recurrent thematic categories that are found 
within the body of knowledge written about the DNP. The first realm was of education and academic concerns; issues included faculty shortages, tenure, academic acceptance, and curriculum essentials. The second category pertained to the clinical practice area and included matters of titling, credentialing, licensing, regulation of DNP practice, cost effectiveness, and the DNP impact on patient care. Finally, the third area was comprised of professional issues, or what Lewis described as concerns relating to coequality versus marginalization, debate over the need for the DNP degree, and the DNP identity or role among interdisciplinary healthcare teams. As made evident in his summary, the literature revealed a prevalence of epistemological and ontological themes that span individual, practical and professional matters, with emphasis on academic concerns.

\section{History: The Development of Practice Doctorates in Nursing}

A brief summary of pertinent literature will provide context to the evolution of the current DNP and the historical trends in the education of advanced practice nurses. The history of doctoral education in nursing is relatively recent and followed the path of other professions, having its beginnings in the development and standardization of the $\mathrm{PhD}$ (doctorate of philosophy). Although the first doctoral degrees for nurses date back to 1924, awarded by Teachers College, Columbia University (Ketefian, Neves, \& Gutiérrez, 2001), these educational programs were initially developed to train nursing faculty and administrators, and provided little coursework related to the practice of nursing. Graduates were awarded PhD or EdD degrees in education, not nursing (Carter, 2013). Further movement to establish nursing-specific doctoral degrees occurred in the 1950's 
after a multi-professional debate concluded that the $\mathrm{PhD}$ degree should be the recognizable, gold-standard terminal degree for all professions (Carter, 2013). Simultaneously, the way nurses were being prepared was dramatically altered from the hospital ward apprentice model of training to the education provided in the academic and scholarly setting of a university. This change created two significant shifts: 1) it rewarded students with a formal degree that was commensurate with their skills and knowledge, in lieu of a non-transferable diploma; and 2) it required nurse educators to meet strict university standards, both for faculty education requirements and curricula criteria. The latter was instrumental in the development of doctoral nursing degrees, as the doctorate is the prerequisite for university tenure track faculty positions. Prior to this transition few, if any, nurses held master's degrees and almost none had doctorates in nursing (Carter, 2013). A major nurse theorist in the 1960's, Martha Rogers described nursing as being "abysmally short of philosophers" and repeatedly stated there was a "grave need for PhD programs with majors in nursing" (Rogers, 1966, p. 75).

Although some baccalaureate nursing programs had existed since the 1930's (nursingeducationhistory.org), the profession of nursing had not yet developed its own doctoral programs and, prior to 1970 's, only educational doctorates or basic social science PhDs with a minor in nursing were available to nurse scholars (Carter, 2013). The 1970's saw the development of many new doctoral programs in nursing with this growth extending through the next several decades. By the year 2000 there were 75 doctoral programs, with the $\mathrm{PhD}$ remaining the most commonly awarded degree (McEwen \& Bechtel, 2000). 
In response to the growth of the $\mathrm{PhD}$ degree in the mid-twentieth century, professions wanting a practical degree without a focus on research or education began developing practice doctorates such as the doctor of osteopathy (DO), doctor of medicine (MD) or the doctor of dental medicine (DMD). Nursing did as well, and in 1960 Boston University designed the first nursing doctoral degree that focused on clinical practice, the doctor of nursing science (DNSc). Other universities followed suit: the University of Pittsburg created a PhD in clinical nursing; the University of Alabama at Birmingham developed a doctor of science of nursing (DSN) in 1975; and in 1979 Case Western Reserve University developed the first entry-level doctorate, the doctor of nursing (ND), (AACN, 2006; ANA, 2011; Carter, 2013). Over time, however, the DNSc and DSN degrees became indistinguishable from the $\mathrm{PhD}$ with regard to the curriculum and dissertation topics (Dennison et al., 2012; Flaherty, 1989; McEwen \& Bechtel, 2000) and eventually most colleges consolidated or phased out other programs in favor of the $\mathrm{PhD}$. Nonetheless, ideological support for practice doctorates continued within the profession bolstered by writings such as Schlotfeldt's instrumental article "The Professional Doctorate: Rationale and Characteristics" (1978).

Echoing similar support for the practice doctorate, Christman wrote in 1980:

Imagine how different the present level of clinical care might be if all nurses had earned professional doctorates for at least the past two generations. Compare that mental reflection with the harsh reality that only two-tenths of one percent of the nurses of this country are prepared at the doctoral level. It is almost impossible to 
be an equal contributor when the present relative deprivation of training exists between nurses and other major providers of care, (p. 31).

Other authors also continued to support the practice doctorate including Newman (1975), Grace (1989), Fitzpatrick (1989), Pearson, Borbasi and Gott (1997), Vesser, Stegbauer and Russell (1999), and Mundinger et al. (2000). Despite this backing, the remaining ND programs were overshadowed by the growth of the research-focused $\mathrm{PhD}$ and by the year 2000, the ND was only offered in four institutions and its conceptualization as an equal to the MD had become ambiguous and unsupported (Lenz, 2005; McEwen \& Bechtel, 2000).

Interest in a practice doctorate in nursing remained, yet lack of collaboration between institutions of higher learning and professional organizations prevented any significant consensus (McEwen \& Bechtel, 2000). Eventually, due to growing confusion regarding the nature of existing practice doctorate programs, a task force was convened by the $\mathrm{AACN}$ in order to examine trends in practice doctorate programs, to clarify the need for, purpose of and goals of the practice doctorate, and to make recommendations for the future. These recommendations were subsequently released in 2004 as the now consequential Position Statement On The Practice Doctorate In Nursing. This release once again renewed interest in, and debate over the creation of a practice doctorate in nursing, now termed the Doctorate of Nursing Practice (DNP).

\section{The DNP, Support and Scrutiny}


Literature concerning the DNP, and APRN education in general, has increased exponentially through collaboration between professional nursing organizations and educational institutions for nursing. During, and shortly after the AACN's publication regarding the DNP, a new surge of reciprocating commentaries and articles were released from scholarly individuals and institutions alike. Writings contemplating the DNP were often hypothetical in nature, and frequently used provocative titles such as "asset or albatross?", "innovation or disruption?" and "future or fringe?" (Carlson, 2003; Chase \& Pruitt, 2006; Marion et al., 2003). An early and often cited commentary from Dracup and Brown (2005) was titled: Doctor Of Nursing Practice, MRI or Total Body Scan? This essay discussed the advantages of the DNP as well as some pertinent concerns with the timing and public opinion of this degree, wondering if the DNP was the "right degree for the right time, or if it was to become like the body scan, a fad lost in time" (p. 280).

Momentum for the development of the DNP grew; endorsements were provided by nursing organizations including the National Organization of Nurse Practitioner Faculty (NONPF), American Nurses Association, (ANA), the American Academy of Nurse Practitioners (AANP), and publications supporting this new role began to circulate in the literature. Articles including "Moving Forward Together: The Practice Doctorate In Nursing” (O’Sullivan, Carter, Marion, Pohl \& Werner, 2005), “The DNP, A Natural Evolution" (Partin, 2005), and "The Practice Doctorate In Nursing: An Idea Whose Time Has Come" (Lenz, 2005) provide evidence that a growing number of professionals were ready to advocate for this degree. These authors, along with many others, demonstrated positivity and a certain readiness for action to move this degree forward. Writing with 
self reflection and a willingness to learn from past mistakes, they embraced the development of a practice degree and defended its appropriateness and validity (e.g. Apold, 2008; Burman, Hart, \& McCabe, 2005; Brown-Benedict, 2008; Clinton \& Sperhac, 2006; Hathaway, Jacob, Stegbauer, Thompson \& Graff, 2006; McLoughlin, 2006; Mundinger, 2005; Olshansky, 2004; \& Rowberg, 2005).

Concurrently some articles were published that presented another perspective. Speculation regarding the need for the DNP degree, the academic and professional implications, as well as the ramifications on current APRNs began to generate significant consternation. Meleis and Dracup (2005) both expressed concern and identified significant issues surrounding social and professional implications of this degree, cautioning for more integration and less fragmentation among advanced nursing and calling for a renewed focus on the thriving and well understood MS and PhD degrees. Fulton and Lyons (2005) debated the rationale and need for the DNP, describing the existence of confusion concerning the focus of this degree, as well as the impact on educational and economic resources citing a variety of regulatory issues. They described this DNP movement as creating a major paradigm shift within the profession that demanded a more thoughtful and deliberate dialogue prior to realization.

Also advocating for a more prudent approach to the American Association of Colleges of Nursing's (AACN) DNP recommendations were two essential articles titled Reflections On The Doctorate Of Nursing Practice, (Dracup, Cronenwett, Meleis \& Benner, 2005) and The Doctor Of Nursing Practice: A National Workforce Perspective 
(Cronenwett et al., 2011). In the first article, the authors welcomed the renewed interested in a practice doctorate but expressed significant uncertainty about the social and economic benefits of the degree, the potential for further faculty shortages in academia, and the exacerbation of the already critical shortage amongst the APRN practitioners. Also, highlighting the curricular variabilities among DNP programs, titling, and the discrepancies that then existed between the NONPF and AACN recommendations, the authors suggested that this new degree would further engender confusion among educators and APRNs alike. Additionally, the overall lack of national support among faculty members, later validated by Brown and Kaplan (2011), patient confusion over the role of the APRN, and the apparent divergence from the competent and accomplished master's programs all purportedly would have destructive consequences on societal image of the practice of nursing and further jeopardize the legitimacy of the nursing role.

Following this article, the National Workforce Perspectives paper (Cronenwett et al., 2011) described the advanced nurse's role as a public good and examined it within the context of the chaotic healthcare system, waning economy, and changing societal demands. An in-depth analysis of fundamental issues associated with healthcare reform, access to care, quality, cost and sustainability concluded with recommendations on how the profession might best serve the public's needs while ensuring the continued development of advance practice nursing. Recommendations included that the master's level programs should continue to be offered, valued, and accredited, while continuing to be the entry-level degree required of APRNs. 


\section{Current status of the DNP}

Although DNP programs continue to rapidly increase in numbers, the current adoption of the DNP remains somewhat hesitant and the recommendation that all APRN education lead to a DNP by 2015 unattainable. While opinions related to this proliferate in the literature, professional organizations have been cautious about wholeheartedly endorsing this degree, especially with regards to the 2015 timeline. According to Bellini and Cusson (2012), there is little firm support for the AACN's recommended implementation date of 2015 amongst the advanced practice nursing organizations. What is occurring instead is that educational programs are gradually changing their curriculums (a slow process even when done in an expedient manner) and professional certifying bodies are establishing their own future dates by when applicants to take certification examinations must have the DNP credentials.

Organizations representing the four advanced practice roles as delineated in the AACN's Consensus Model For APRN Regulation: Licensure, Accreditation, Certification And Education (2008), (Certified Nurse Practitioners [CNPs], Certified Nurse Midwives [CNMs], Certified Registered Nurse Anesthetists [CRNAs] and Clinical Nurse Specialists [CNSs]) have all released position statements demonstrating varied levels of support. The American Association of Nurse Practitioners (AANP) supports the concept of transitioning to doctorally trained APRNs, while placing emphasis on issues surrounding the transition and the continued need to ensure safe, high quality nursing care. The discussion paper, revised in 2013, appears to support the transition by stating 
that "it is clear that the course work currently required in NP master's programs is equivalent to that of other clinical doctoral programs" and that "the evolution of existing master's programs to practice doctoral programs can add strength to programs and NP practice, and can increase recognition in the health care arena", however does not mention the 2015 recommendation date. It also positively endorses and supports current masters programs and practicing APRNs by stressing that "current master's and higher degree NP programs fully prepare NPs ...for health promotion, as well as the management of patients with undifferentiated problems and those with acute, complex chronic, and/or critical illness." (AANP, 2013).

Similarly, the National Association of Clinical Nurse Specialists holds a position of "affirmed neutrality" (2009), and continues to support the DNP as being optional for entry to practice while believing that "CNSs are already well prepared educationally to practice advance nursing" (2009). The organization endorses either masters or doctorally prepared graduates as being eligible for credentialing (2009).

The International Society of Psychiatric Nurses (ISPN) neither endorses the doctoral recommendation for entry into practice nor the 2015 date, stating that "a more flexible transition would better serve the needs of major stakeholders" (Postmontier et al., 2013 p. 59). The American College of Nurse Midwives (ACNM) also does not support the AACN's recommendations stating it there exist contradictions to the AACN's own Consensus Model. Citing inconsistencies in language in both statements, the ACNM states that in the Consensus Model it is stipulated that for certification APRNs need to 
hold a graduate degree, not necessarily a doctorate (ACNM, 2011). Finally, the National Association of Nurse Anesthetists (AANA) fully endorses the DNP degree and the AACN's recommendations, however has delayed the required implementation date until 2025, after which a practice doctorate will be required for entry into practice (AANA, 2007).

Ultimately, it is important to note that while debate and controversy exist surrounding some aspects of the DNP (e.g. DNP specific outcomes, nature of the DNP, implementation date of a requirement for that level of preparation, and the definition of clinical experience [Grey, 2013]), overall support for the implementation of the degree and the continued presence of a practice doctorate in nursing appears to exist among most professional organizations and academic institutions (Grey, 2013). Areas of consensus and high interest in pursuing the DNP exist within the profession and employers. There is an acknowledged need for advanced nurses to increase their role in health care leadership and the importance of higher levels of education among nurses (Grey, 2013) that may encourage some currently certified APRNs to pursue this rigorous degree.

\section{The DNP: Student Experiences}

Undergraduate and PhD nursing student experiences have been examined at length as revealed when a database search of nurse student experience resulted in nearly 3000 entries. Few articles examining the experiences of APRNs in DNP programs were found within this collection. Most of the articles referencing practice doctorate students or doctoral student experiences were written by and intended for nursing faculty 
members, and were primarily focused on how to best educate doctoral students in practice doctorate programs (e.g. Lee, 2009; Montgomery, 2011). As relatively new adopters of the DNP movement, students who have decided to pursue this degree are poised to lead others through the sharing of their experiences, challenges, and successes. Studies of the factors contributing to the decision to pursue this degree and the lived experience of the students who have done so have been insufficiently reported in the literature. The demographics of students pursuing nursing doctorates have been reported as mainly older than their peers in other disciplines (typically in their 40s), with established careers, family responsibilities, and as a result are usually only able to commit to part-time study (Halter, Kleiner \& Hess, 2005). This population also warrants further study.

Articles and studies in closely related areas of interest can add context and contributions to this literature review. Arvidsson and Franke (2013) recently reported on a phenomenological study that examined the experiences of nurses in $\mathrm{PhD}$ doctoral programs as they transitioned from clinicians to researchers, however did not include students studying in a practice doctorate program. They sought to reveal how practicing clinicians perceived their developing and changing learning processes during their $\mathrm{PhD}$ education, as well as how they viewed their role transition from a clinician to a researcher. Salient themes that emerged were "developing preparedness for action within the nursing profession" and "a learning process where practice problems are integrated and problematized in relation to scientific theories" (p. 55). While valuable in 
contributing to the body of knowledge surrounding $\mathrm{PhD}$ student experiences, it does not provide information related to the experiences of students pursuing a DNP.

Lee (2009) examined the practice doctorate students' experiences and perceptions regarding research supervision in the United Kingdom (UK). Students and educators were interviewed and data was gathered regarding their experiences with faculty supervision while attending a professional doctorate program. Using observation and group workshops, interviewees described issues experienced during the supervision process that were of high significance to students and educators alike. Derived from these issues, themes emerged associated with posturing (individual attitudes or behaviors), partnership and equality, supervisory styles, and pragmatism. Students described wanting focus, guidance and structure, while also desiring challenge, independence and partnership with their faculty. The implications of this study demonstrated a need to develop courses that will enhance the benefits of supervision as well as the continued development and implementation of effective supervision frameworks within nursing programs. Faculty were encouraged to pursue a practice doctorate in order to provide greater diversity within practice doctorate programs and to better meet student needs (Lee, 2009). It was also implied that strategies that assimilated professional practice with academic knowledge, such as practice residencies, were a significant contributor to enhancing the use of supervision in programs (Lee, 2009). As there are current discussions surrounding the benefits of residencies for ARPN graduates (Instone \& Palmer, 2013; Shelby, 2008; Wall, Novak \&Wilkerson, 2005), this study may provide insight for students and faculty engaged in this education process, as well as 
providing some guidelines for the development of new strategies in the use of professional supervision within graduate programs.

New teaching approaches designed specifically for the DNP student were described in Montgomery's 2011 article. While not discussing student experiences per se, the article provided valuable observations of innovative DNP-oriented curricula that may inspire tentative applicants and provide some understanding of program expectations. Curricula heralded as being flexible, self-directed, and active in experiential learning while maximizing the use of technology, peer feedback and teamwork, may stimulate and invigorate students, and help to recruit hesitant APRNs facing a lengthy program of study.

Also found in the literature, and relating to nursing doctorate student experiences were articles by Halter, Kleiner, and Hess (2005), which examined online learning experiences and the benefits of this relatively new learning modality; and Evans and Stevenson (2009), who conducted a literature review summarizing the experiences of international nursing doctoral students. While contributing to the description of doctoral nursing student experiences by providing observation into their selected areas of interest, neither article examined APRN experiences in practice doctorate programs.

Resop Reilly and Fitzpatrick (2009) studied the experiences of DNP students as relating to their stress and sense of belonging while enrolled in a doctoral program. Describing the stress of doctoral education as a "roller coaster of affect, behavior and attitude changes" (p. 81), they described many nursing students as unprepared and 
unaware of the challenges that doctorate programs present. A student's sense of belonging was defined as "the psychological experience of fit and valued personal involvement in a system" (cited by Resop Reily \& Fitzpatrick, p. 1) and it hypothesized that there existed an inverse relationship linking these two variables. The purpose of the study was to describe the student experiences and to further clarify the relationship between the variables. Using online questionnaires, the authors interviewed 89 female, post-masters DNP students and found that levels of stress within this population to be similar to levels found in previous studies examining levels of stress, and that "a sense of belonging provided a significant buffer against the development of depressive symptoms" (p. 84). As suspected, a statistically significant inverse relationship was found between perceived stress and a sense of belonging. An interesting and unexpected finding was the lack of correlation between a student's sense of belonging and whether or not they enrolled into the program individually, with a colleague or friend, or as part of a larger group or cohort. This finding highlighted the significance of social bonds that were formed within the program, beyond pre-existing relationships between enrollees. Recommendations included the implementation of strategies such as semester-long small group interaction, a more supportive classroom climate, online chat rooms and education regarding stress management which were intended to promote each student's sense of belonging within the academic program. Future research of DNP students' experiences were recommended at all levels.

Finally, a comparable study was found that examined DNP student experiences and explored the contributing factors in the decision making process to pursue a practice 
doctorate. Baldwin (2013) reviewed the literature and identified a need for further inquiry into both the student experiences in this setting and why these participants chose to pursue this degree. Baldwin used a qualitative design and a grounded theory approach with the intent of generating an inductive theory. Interviewing five students using semistructure open-ended questions she identified the main influences that students reported as factoring into their decision making process, the mutual challenges experienced by the students, and core concepts that existed.

Influences to pursue the practice doctorate included statements such as: "be taken seriously," "impress others," "respect and admiration," "personal challenge" and "pride in achievements." Personal development was an influential characteristic as students were described as having "a desire to learn, develop and achieve more" (p. 479) and students also described that pursuing the practice doctorate added to their personality and enhanced other people's perceptions of them, a significant motivator in all participants. One student felt that pursuing a doctorate was "also good for the profession in that it challenged the stereotypical view of nurses held by others." From these statements, Baldwin conceptualized themes of personal development, professional development, and perception of others. These concepts were accurately reflected in the students' statements expressing a desire for more career opportunities, higher clinical positions, and professional development in terms of both leadership and research skills, as well as confidence in their current position. 
Challenges discussed related primarily to family, social interactions, and time commitments. Balancing work, personal life and academic responsibilities were expressed in statements such as:

"I work full time as a manager of my department. At the same time I have to look after a house and I have to fulfill my role as a wife, my social life, my family and being a student ... it seems that its quite a lot ... I won't neglect any of them so this is quite challenging" (p. 481).

Students identified the coping mechanisms that they used to face such challenges. Strategies highlighted included time management skills, discipline, good support systems and having adequate time to study (p. 481). From these generalized categories, the core concept of her grounded theory was developed and defined as a desire to enhance professional and personal identity while being faced with numerous challenges (p. 482).

The application of Baldwin's research and findings were summarized in some key points, the first being that nursing doctorates remain under-researched and this research, along with the understanding of student experiences are important in shaping future curricula. She described her study as contributing to the current body of knowledge and “informative for future students, academic staff and other practitioners involved with nursing doctorate programmes" (p. 482).

Baldwin also concluded that: 
“the professional doctorate, while enhancing professional and personal identity, is the ideal programme where nurses can develop as expert clinicians, leaders and researchers in order to facilitate change and function effectively in emerging healthcare services" (p. 482).

Baldwin also described a high level of pride, admiration and respect among the students towards this degree, contradictory to previous postulations that the DNP would be a "quick-fix" $\mathrm{PhD}$ or at some level perceived to be below the $\mathrm{PhD}$ in academic status (Beckstead, 2010; Ellis, 2005; Ellis, 2007; Meleis et al., 2005). Baldwin’s study, conducted in London, England, will provide a comparison for this researcher's findings, potential similarities may enhance discussion and unique differences may be contrasted to further add to the body of knowledge surrounding this new topic.

\section{Summary of Literature Review}

The implications of the development of the DNP degree on currently licensed APRNs, academic programs, and the professions' ability to meet the demands of today's healthcare system have been extensively debated in the literature. Professional organizations have made their contributions through publications and position statements; polarized opinions expressing sentiment for and against this new degree have surfaced online, in nursing publications, in responses to editorial pieces, and within the workplace. Few articles have researched the experiences of actual DNP students and the contributing factors in their decision making process that led to their pursuing this degree. Further research is indicated. 


\section{Theoretical Framework}

One of the great attributes of the nursing profession is its ability to adapt to change and to be flexible in a continually evolving and multifaceted healthcare system. Nursing is dynamic; its' versatility and adaptability have been important contributors to its success as a profession and provide the foundation for innovation in education, practice and research. Whether it is the incorporation of innovative technologies in the workplace, the implementation of a new patient care initiative, or the application of an evidence-based standard, nurses have always discovered was to adapt and change to improve healthcare outcomes, persistently rising to meet the rigorous expectations of the increasingly complex and demanding healthcare system.

In an effort to examine the experiences of APRNs who have decided to pursue the DNP degree, the theory of diffusion of innovations (Rogers, 2003) was selected to provide a contextual framework for this study and guide the evaluation of participant responses. Rogers' theoretical insights clarify what qualities enable an innovation to spread successfully throughout systems, how ideas spread from individual to individual or group to group, and what different groups require in order for them to eventually adopt the innovation. According to Rogers (2003), innovations may be new objects, ideas or behaviors and diffusion occurs when these innovations are communicated though certain channels over time, among members of a social network.

A professor of rural sociology, Everett Rogers developed his theory when studying why some farmers adopted new pesticides and why others did not (Rogers, 
2003). His work, "Diffusion of Innovations" was initially published in 1962 and is now in its $5^{\text {th }}$ revision. It has been borrowed and applied to multiple disciplines and used in more than 6000 research studies, becoming one of the most reliable theories in the social sciences (Robinson, 2009).

\section{Theoretical elements}

Elements of Rogers' theory include:

a. Innovation: "an idea, practice or object that is perceived as new by an individual or other unit of adoption" (Rogers, 2003, p. 12). Innovations require five qualities for success:

- Relative advantage - the change is perceived as advantageous to the group.

- Compatibilities with existing values and practices - the change must "fit well" with the group.

- $\quad$ Simplicity - change must be simple to understand

- Trialability - change must be able to be easily piloted to remove uncertainties

- Observable results - visible results stimulate adoption.

b. Communication channels: "the means by which messages get from one individual to another" (Rogers, 2003, p. 18). These channels may be a form of mass media or, more effectively, the exchange of information between two social 
individuals. He states that most people do not evaluate innovations or their consequences based upon objective scientific sources, but do so based upon the subjective report of another who has already adopted the innovation, i.e. word of mouth (p. 18).

c. Time involved in three distinct yet related facets:

- The innovation-decision process by which an individual passes from first knowledge of an innovation through its adoption or rejection. The innovation-decision process is compromised by five steps: knowledge; persuasion; decision; implementation and confirmation.

- The relative innovativeness of an individual or unit compared with other individuals or units (i.e. the earliness or lateness that the individual or unit adopts).

- The overall rate of adoption of the innovation within a system, as measured by the number of members who adopt the innovation within a given time period (Rogers, 2003).

d. Social system: as defined by "a set of interrelated units that are engaged in joint problem solving to accomplish a common goal (Rogers, 2003, p. 37). Social systems have patterned arrangements or structures, which give stability and regularity to individual behavior. Innovations present a sense of uncertainty and 
systems therefore may facilitate or impede the diffusion of the innovation within the system (Rogers, 2003).

\section{Theoretical concepts}

Concepts of Rogers' theory include:

a. Reinvention: the success of the new innovation must be adapted and redefined to meet the needs of more demanding and risk-averse adopters.

b. Peer-peer conversations and peer networks - the concept that marketing methods spread information, conversations spread adoption; people trust people more than they trust ideas or innovations (hence the use of opinion leader tactics - e.g. "champions").

c. Understanding the needs of different user segments - each group has its own personality and requirements that must be met before they adopt a change. Each group adapts to change based on its strengths and limitations. d. Diffusion of innovation does necessarily ensure adoption of the innovation.

\section{Categories of adopters}

Individuals or groups are categorized within the social system on the basis of their speed of adoption and innovativeness. Rogers identifies five categories of adopters whose rate of adoption, when plotted, follows a normal distribution and the standard deviations of the traditional bell curve: 


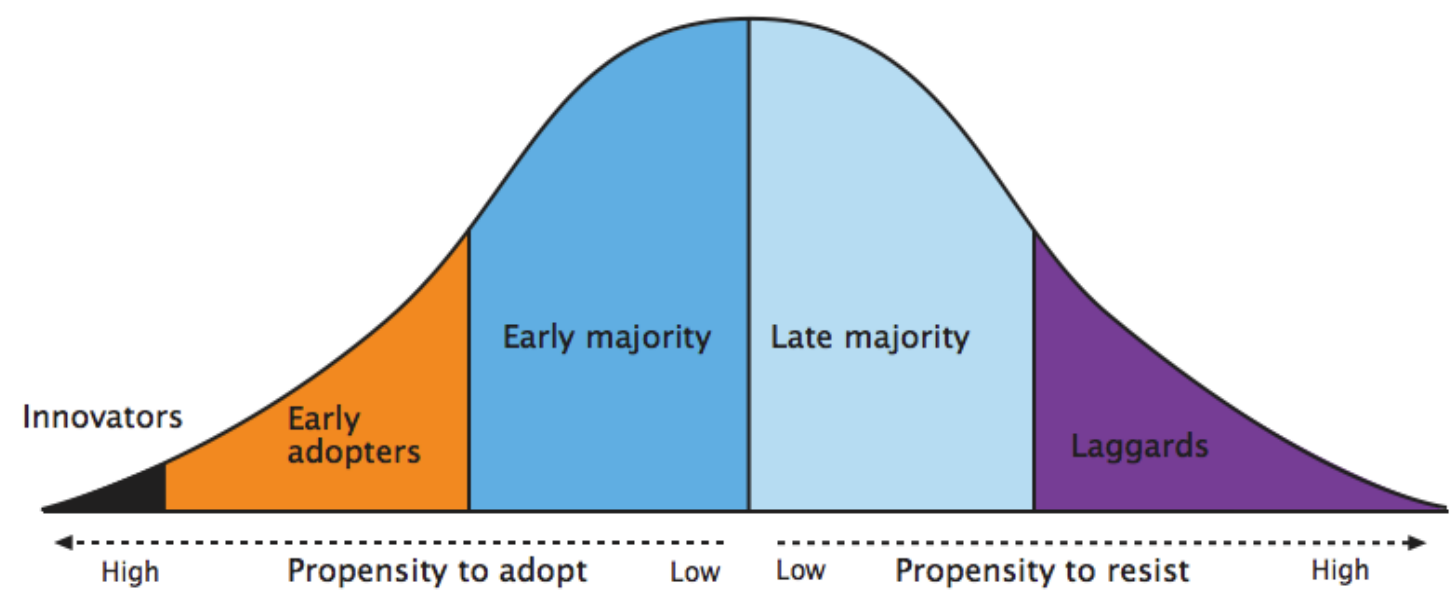

(Robinson, 2009).

a. Innovators -the first individuals to adopt the innovations. They are generally younger, of higher socioeconomic status and very social; they comfortable with risk taking and with financial loss. The innovator plays the role of gatekeeper in the flow of new ideas into a system.

b. Early adopters: more integrated in the system then the innovators, considered localites. They are the second fastest, right behind and in close contact with the innovators. They have a high degree of opinion leadership, garner respect from the majority of individuals, are viewed as the go-to-people and serve as role models. They are often are viewed as putting their stamp of approval on the innovation and they trigger a critical mass when adopting it.

c. Early majority: just before the average, these members adopt slower than early adopters and are characterized by adopting deliberately and willingly, however 
seldom rapidly. They are not the leaders yet form a large percentage of the total population, approximately one third. This group provides a vast amount of interconnectedness within the system and is an important link in the diffusion process.

d. Late majority: members of this group approach innovation with skepticism and caution. They will adopt only after uncertainty and risks are mitigated. Peer pressure and economic necessity motivate this group. Socioeconomic status is somewhat lower than earlier adopters. The late majority, just as the early adopters make up approximately one third of the members of a system.

e. Laggards: the last group to adopt an innovation; these members are characterized by being traditionalists, lack any opinion leadership, are often the social isolates in the system and use the past as their point of reference. They tend to be suspicious of change or change agents and their innovation-decision process is lengthy. Resistance occurs in part because of a general lack of risk taking behaviors due to their limited resources, as well as their limited contact with earlier adopters and "delayed knowledge-awareness of the innovation" (Rogers, 2003).

\section{Social Change}

Rogers' theory provides a solid framework for exploring the concept of change and helps to explain the process behind the introduction and adoption of an innovation by 
individuals and how new innovations are taken up by a population. The theory offers three valuable insights into the process of social change by describing:

a. The qualities that make an innovation spread successfully.

b. The importance of peer-peer conversations and peer networks.

c. The variable needs of different potential user groups.

\section{Application of theory}

Rogers' theory (2003) provides the context for exploring why APRNs have adopted and pursued this relatively new DNP degree, what characteristics may be similar among them, and what social networks may have played a role in their decision to pursue the degree at this point in their careers. The actions of these nurses demonstrate characteristics of innovators or early adopters of this degree and analysis of their responses may provide insight into the value of this educational pathway for advance practice nurses and how the profession may further recruit nurses into doctoral programs. 


\section{Methods}

The purpose of this descriptive study was to describe the experiences of an aggregate of current APRNs who have chosen to pursue the DNP degree, and the personal or professional reasons they decided to do so.

\section{Design}

This descriptive, exploratory qualitative study used semi-structured e-mail interviews to obtain data. Interviews were guided by open-ended questions. Outreach to individual participants began on October $30^{\text {th }}, 2014$, after the RIC IRB approval was

obtained and continued during the data collection period lasting up to January $20^{\text {th }}, 2014$.

\section{Sampling method}

The sample was a non-probability, convenience and purposive sample comprised of 1) APRNs who were practicing clinically, who had a master's degree and who were currently enrolled in a DNP program, and 2) APRNs who had completed a practice doctorate within one year. Exclusion criteria included students obtaining the doctoral degree via a BSN-DNP track, other non-DNP programs, or APRNs that completed a DNP program prior to 2012.

Outreach to potential participants began through word of mouth to the researcher's personal and professional contacts and employed the use of snowballing. Contacts recruited to aid in the snowball process included four APRNs that were personal colleagues of the researcher, five individuals from five local DNP programs (University of Rhode Island, Rhode Island College, University of Massachusetts at Dartmouth, 
University of Massachusetts at Worcester and Boston University) and a member of the Rhode Island State Nursing Association.

\section{Procedures}

Potential participants were provided with a business card with the title of the project and researcher's academic email address. Potential participants were forwarded the IRB approved informational letter after they contacted this researcher expressing a desire to participate. This letter included the study purpose, procedures, and what was expected of them. Participants were offered the option of choosing to create a generic, unaffiliated email address for the purpose of this study if they choose to remain anonymous. All participants were assured that their contributions would remain confidential. Participants were informed that they could be contacted again for clarification purposes, could abort at any time, and were free to respond at their convenience within the prescribed data collection period. Participants were informed that, if desired, an ongoing email conversation during this time period would be conducted at their convenience to collect data.

\section{Resources}

In an attempt to understand the strengths and limitations of email as a resource, and to add trustworthiness and dependability to the methodology of this study, Opdenakker's analysis (2006) highlighting the advantages and disadvantages of various interviewing techniques in qualitative research was examined. 
Specific strengths and weaknesses of email-based interviews were identified. Strengths included:

a. Extended access to participants longitudinally.

b. The ability to reflect over ones thoughts as answers are formulated.

c. The ability to formulate responses independent of time, place or cicumstances.

d. The cost effective nature of email.

Disadvantages noted were:

a. The lack of control over environmental variables affecting intimacy and privacy.

b. Distractions that may result in casual responses preventing thoughtful and reflective answers.

c. The lack of spontaneity and the potential richness it provides.

d. Email conversations extending over days to weeks may become fragmented and lack the continuity of a face-to-face interview.

e. Participants may lack the support of multivocality normally found in focus or group interviews and subsequent responses may be less comprehensive or rich in detail. 
e. The inability to assess non-verbal communication during the interview (Opdenakker, 2006).

Reflection upon these strengths and limitations guided the researcher through the planning and implementation of the email interviews. With the ability to access participants longitudinally, questions were limited to $2-4$ per email to reduce content overload and to allow for focused, thoughtful responses. Notes of encouragement and personal commentary often preceded questions to promote a positive atmosphere in the conversations. Other examples of the application of these strengths were the researcher's attempts to respond within a 24 hour period to maintain a more consistent and fluid conversation, and the effort to promote continued engagement by acknowledging, commenting on, and thanking the participants for their latest contributions.

Challenges were also reviewed in an effort to recognize potential obstacles in the data gathering process inherent to email. Emoticons were employed judiciously to relay sentiment, and again, the rapid turn around time on the researchers behalf was intended to minimize fragmentation and distractions. Where appropriate, the researcher's personal thoughts and experiences that dovetailed with participant responses were also shared to build a positive relationship with the respondent, while demonstrating support through multivocality.

\section{Ethical Concerns}

Rhode Island College IRB approval for the project was obtained. Information that could identify the participants' colleges or programs was not collected to protect both 
the institution and the participant, as some respondents may have had negative experiences that could have potentially presented a conflict of interest. All information was collected confidentially and remains so. Data were collected by logging electronic conversations and secured by the researcher in a confidential manner employing data encryption software on an external hard drive. Original email transcripts were deleted from the researchers account once logged on the device. All interviewing, data securing and storing was completed by the researcher. Data were password locked and only accessible to the researcher. Data will be stored for as long as required by the IRB and then deleted permanently.

\section{Measurement}

Demographic information for potential eligibility was obtained from each participant to describe their qualifications, APRN role in their clinical setting, professional experience, and their current phase in the DNP process. Questions included:

a) Are you currently enrolled in a DNP program? If yes, describe your standing as a student $\left(1^{\text {st }}\right.$ year, $2^{\text {nd }}$ year, $3^{\text {rd }}$ year etc $)$. If no, do you currently have a DNP degree? If yes, please list the year you graduated.

b. Please describe your current area of practice or specialty.

c) Please describe your role as an advanced practice nurse in your clinical setting.

Following this introduction, the primary questions used in obtaining data was "what factors contributed to your decision to pursue this degree" and "tell me about your 
experiences as a DNP student”. Further questions followed for purposes of clarification, insight and conceptual development, based upon the participant's willingness to respond.

\section{Data Analysis}

As qualitative data analysis is iterative and continuous, the collection, analysis and interpretation of the data collected was conducted as the interviews were carried out, among multiple participants at a time. Data obtained in the form of email text was categorized into groups with recurrent ideas and words tabled, with subsequent themes derived. A descriptive phenomenological approach was used in content analysis to describe and participants statements. Phenomenology, as detailed by Mateo and Kirchhoff (2009) focuses on the layers of meaning that the individual gives to the experience and tends to go beyond the data in the form or words to identify underlying

significance. An underpinning of phenomenology is that both the reality experienced and the individual living the experience are both involved in shaping each other; in other words, the reality contructed by the individual is influential in creating the individual as he or she lives through the experience. In this manner of qualitative study, a first-person point of view into the intentionality of the APRN's decision to pursue this degree may be learned and the connections and relationships between words, categories and themes produces a discussion of significant ideas and meaning statements that may dynamically relay the APRN's lived experiences as they pursue the DNP degree.

\section{Trustworthiness}


Contrary to quantitative research which uses rigor and validity, qualitative research perceives data as credible and trustworthy. Initally developed by Lincoln and Guba in 1985 and subsequently expounded upon in their later writings, the concept of trustworthiness is identified as being based upon five principles; credibility, dependability, confirmability, transferability and authenticity (Lincoln \& Guba, 1985). Credibility is described as the truth of the data, ensured by accurate representation by the researcher and is validated by having the data recognized by other individuals sharing similar experiences. Dependability refers to the ability to replicate the study with similar participants, conditions and findings. Confirmability is described as the researcher's ability to exhibit how the conclusions and findings were obtained solely from the data without influence from personal bias. This is often best accomplished by using quotes that accurately represent the results and add that also context and substance to the derived themes. Transferability refers to ability to generalize results and apply them to other groups, and finally, authenticity refers the researchers ability to relay the participants story, emotions and experiences with integrity. This is similarly through quotes and direct statements that enhances the richness of the data (Cope, 2014).

Trustworthiness is established using a combination of member checks, interviewer corroboration, peer debriefing, prolonged engagement or bracketing (Holloway \& Wheeler, 2010). Efforts to ensure trustworthiness included prolonged engagement, persistent observation with close attention to the emotional response of participants, and personal journaling, also described as reflexivity or the use of bracketing, to remove preconceptions and subjectivity (Cope, 2014). A clear audit trail 
was maintained during this research process including review by a peer, and a second researcher validated the results independently. 


\section{Results}

The snowball approach led fourteen APRNs to respond with a desire to participate. Of these fourteen volunteers, just seven respondents participated in active email conversations and provided the data for this study's population.

Data were depersonalized and coded both by respondent and by question. For example, the response obtained from participant \#3 to question 2 was coded as response 3.2. Individual responses to each question were combined and tabled. The results, in the form of concise statements, were contrasted and compared with sentiments and concepts highlighted. Some overlap existed as some statements could be representative of several different themes. From these grouped statements, themes were extrapolated and identified. Five major themes were established: personal development, achieving personal goals, professional advancement, program attibutes and relationship with others. Figures and results are displayed below. 
Figure 1. Personal development

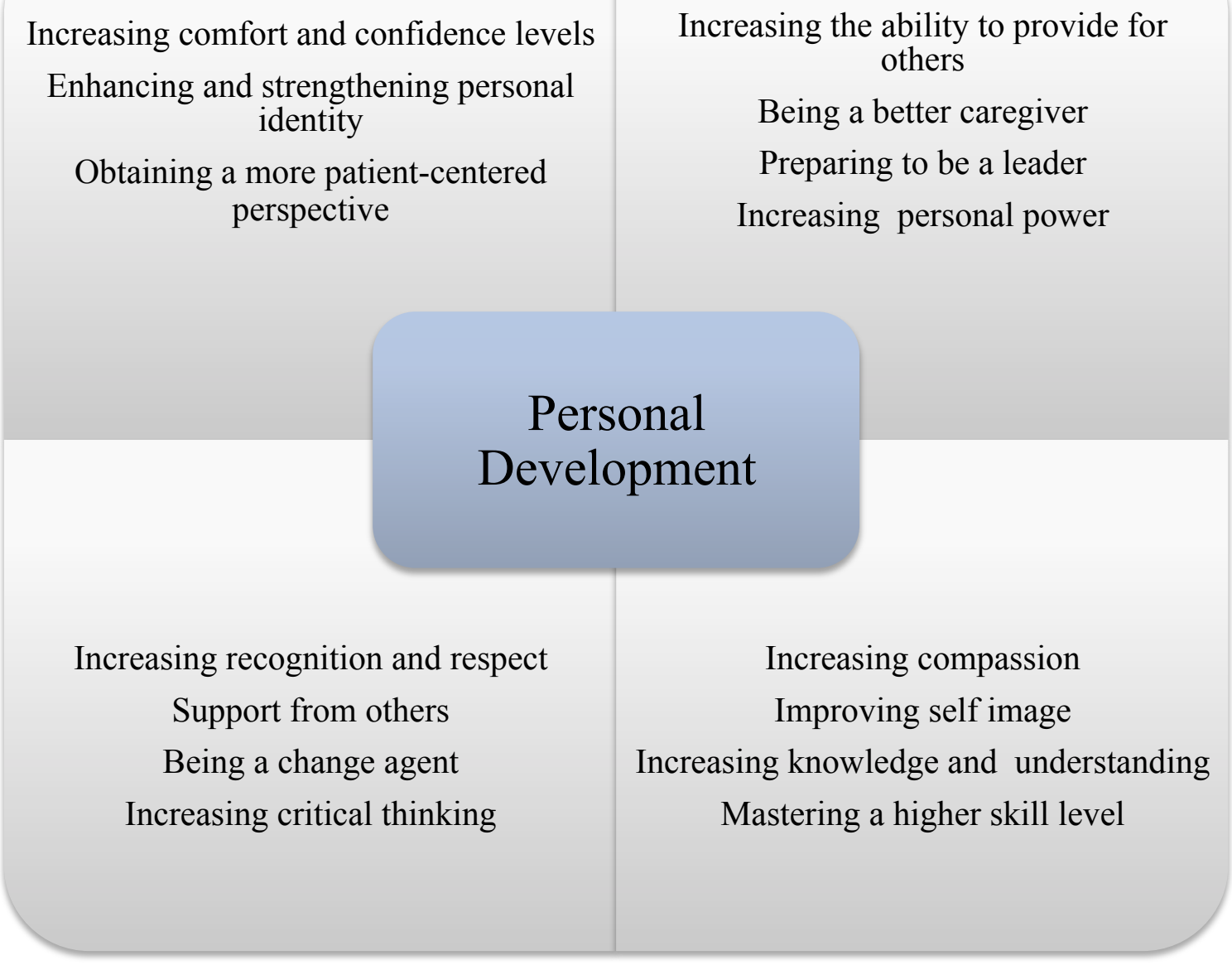

The theme of personal development was common to all participants. Personal growth and development was evidenced by statements reflecting a personal evolution during this process; growth in areas of confidence, knowledge, and insight into global health related challenges were all evident in the student interviews. 
Figure 2. Achieving personal goal

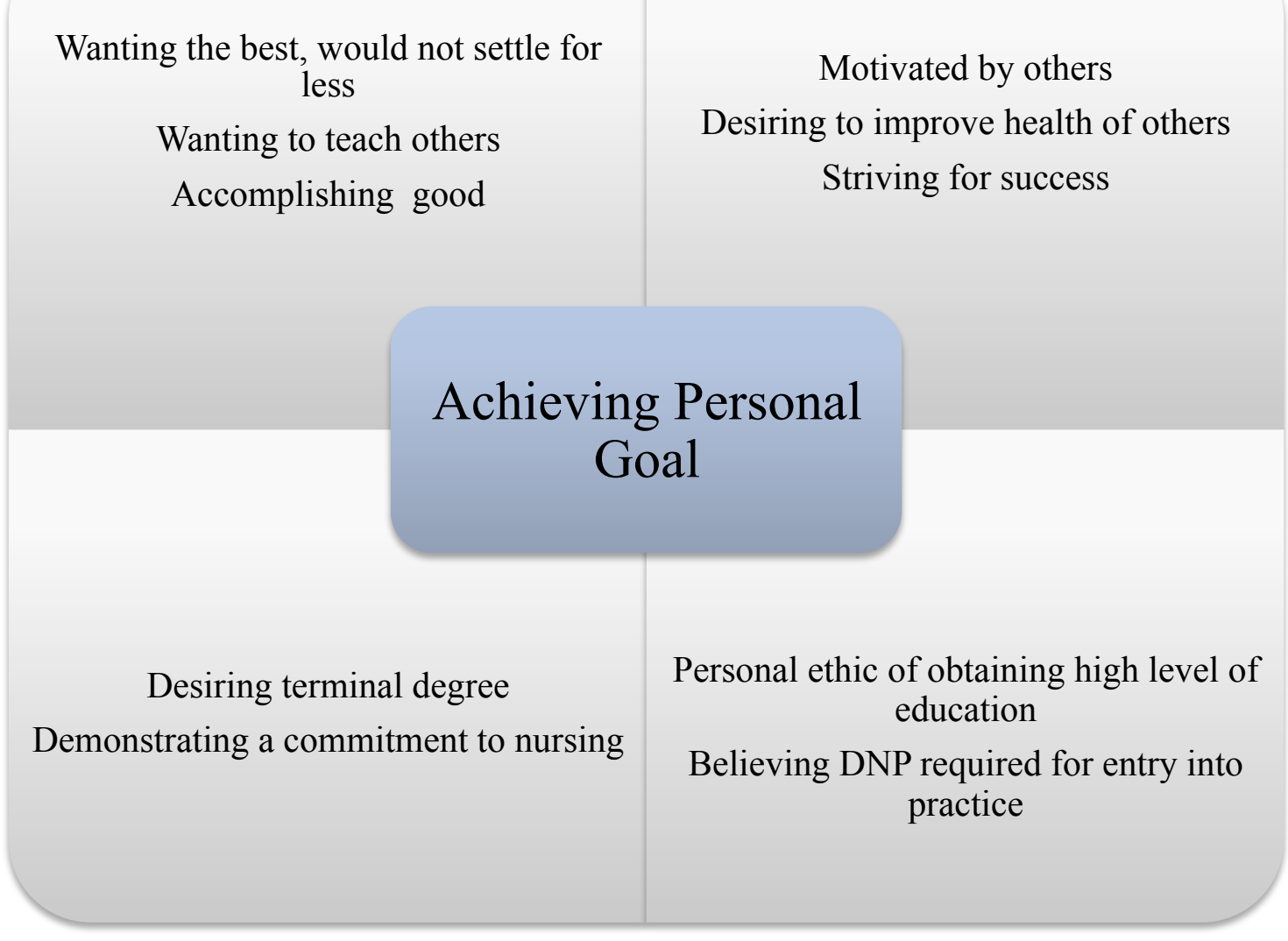

A second theme conveyed by many of the participant's statements was the desire to pursue and achieve a personal goal. This goal was either the DNP degree itself or a goal directly facilitated by the degree, such as a new job opportunity, self-fulfillment via a terminal degree, or simply an altruistic desire to effect change within the healthcare system.

Another explicit theme derived from the interviews, and probably the most overt and tangible theme was that of professional advancement. Whether it was directly tied to a promotion within the workplace, an opportunity in the community or to enable teaching 
at the graduate level, most participants were clear that this degree would directly impact their careers in a positive way. Other benefits included a more distinguished professional identity, broadening one's influence amongst peers and commanding more respect at the workplace.

Figure 3. Professional advancement

Increasing opportunities

Staying relevent in a changing healthcare environment

Demonstrating a commitment to nursing

Increasing power and influence
Increasing recognition and respect from others

Securing a more desirable role

Establishing self in academia

Networking, partnerships

\section{Professional advancement}

Staying competitive

Mastering a higher skill level

Being a change agent in nursing

Securing a future in nursing
Believing DNP required for entry into practice.

Increasing autonomy

More equality with physicians

Improving patient care 
A fourth theme was revealed as a reoccurring topic of reflection amongst the students. This topic centered on the characteristics of their program structure and the challenges and facilitators of their learning environment. The concepts of time management, communication with faculty, distance versus classroom learning, the amount of work expected and other program specific issues were grouped and thematically expressed as program attributes.

Figure 4. Program attributes

\section{Cost}

Advantages of online learning

Faculty support

Positive experience

Satisfying experience
Conflict among varying perspectives Feeling detatched due to online environment

Surprised by focus on research

Expectations met

Communication with others

\section{Program Attributes}

Overwhelming workload

Struggling to meet deadlines

Capstone clinically focused

No benefit to clinical skills

Rigorous
Differing backgrounds increased richness of discussion Creative dialogue Faculty response times Time management 
Finally, participants also repeatedly discussed the concept of relating with other individuals and the ability to garner support from peers, family and friends. Relationships served as the primary source of support for the students, whether in the form of prayers and hugs from fellow church members or from team building efforts during group projects. Although the mutuality formed during shared experiences was described as mostly positive, several participants also shared some negative experiences in the form of conflict with their peers and communication challenges with faculty members.

Figure 5. Relationship with others

Boundaries set and respected by others

Personal sacrifices

Lack of group cohesiveness

Family love and respect
Differing backgrounds increased richness of discussion

Feeling detatched due to online environment

Creative dialogue

\section{Relationship with others}

Supportive colleagues

Motivated by peers

Support via discussion boards and intensives

A shared experience
Camaraderie

Advice from others

Insight gained from experience of peers

Teamwork with others

Communication with others 


\section{Discussion}

\section{Personal development}

Common to all seven respondents was the theme that the DNP degree developed one's self. A deeper understanding of the patient experience, a more global perspective of healthcare and reflecting on difficult issues such as the existing disparities in access and quality increased participant's compassion, sympathy and patience. One participant, when sharing how the curriculum has shaped her identity as a nurse said:

This program has pointed out some of the painful challenges in healthcare for the consumer---it's not always easy to understand or access... I found that I see myself more as a partner to the patient - nurses need to embrace their role as partner with the patient and step away from the traditional role which is more of a parent leading a child.

Another area of personal growth was the increase in confidence illustrated in several students' statements. Describing a recent job interview, one participant commented saying "I interviewed Friday for a new position, and led the conversation with confidence, I was selling myself rather than being interrogated. I could have never done this before." Another recent graduate stated "the DNP helped my confidence as I have a higher level of knowledge about multiple aspects of nursing" while yet another student wrote "the DNP has enhanced my comfort and confidence levels and strengthened my personal identity. I am comfortable being a leader." 
Increased personal and professional confidence was identified by the respondents as a major benefit of the educational process. This increased confidence supports an individual's ability to adapt to change and to be successful in the implementation of new ideas and innovations, it is also the hallmark of a leader who will inspire others with creativity, energy and loyalty. Rogers describes the ability of a confident leader to adopt a new innovation in a time of uncertainty as venturesomeness (Rogers, 2003, p. 283). A key attribute of venturesomeness is personal confidence, and this is reflected in the student's pursuit of this new degree.

Improved self-identity as a professional nurse and increased understanding and ability to be a more independent and compassionate caregiver were described by several of the APRNs interviewed. "Nursing is a valued profession, to be taken seriously... we have the responsibility to improve nursing practice and patient outcomes; my self-identity has improved but we must continue to grow."

Several other students described that their identity as a nurse has evolved through a lifelong process, with the DNP being the natural terminal degree. One response that represented this concept was provided by a nurse who was a successful administrator in a large health and human services organization, she wrote: "I consider myself a nurse leader and believe it is important to demonstrate a commitment to lifelong learning... I wanted to achieve the highest level of education in nursing." Her comments echo the sentiment of many others. Motivated by her grandmother's encouragement, a participant 
stated "I work diligently to make her proud of me... I have always wanted to achieve a terminal degree.”

\section{Achieving personal goal}

While somewhat blending both the professional and the personal, the concept of striving for a personal goal was unanimously stated by each student in the cohort. By either overtly stating that the DNP degree was the goal, or by alluding to other personal goals directly facilitated by the degree, all participants shared a specific desired outcome from this educational pursuit. For one student, it was the ability to combine a passion for church and chronic illness into a capstone project that would ultimately enable the implementation of community resource centers in area churches. For another it was to enhance skills as an executive leader in an organization serving over 1000 children and adults with a budget of over 24 million dollars. For yet a third student, the goal was simply to have a terminal degree, the highest possible level of education available. The significance of achieving a personal goal, whether it be a degree or a new employment opportunity was substantiated and confirmed by the students' emphases on sacrifice, hard work and commitment - "giving up fun times, (for) longs nights at the computer and added stress!! - it requires motivation and commitment! - but I have survived!"

As either a direct goal, or as a secondary gain, the concept of being professionally relevant was also expressed by several participants. With the doctorate potentially replacing the masters as the degree required for entry into advanced practice, professional relevance and competitiveness were a significant concern for many students. One 
participant clearly stated that she "would not settle with being grandfathered in as I think I would be less credible to those that have their DNP degree." Others were less direct with their comments but did imply that this degree was not only enabling a goal to be achieved, but also securing a role for the future.

Probably the most common goal among this group of students was the ability to teach at a graduate level. Teaching remained a desire for $85 \%$ of the cohort with four of the seven explicitly expecting to use this degree to advance academically. Two students planned on having a faculty position as an option as their careers progressed and only one student did not overtly state teaching was in her future. Demonstrating the intertwined relationship that existed between their clinical and educational practices, one student chose the DNP program over the PhD degree specifically to be able to use the clinically focused capstone project to affect student outcomes in her faculty setting.

The deliberate decision to pursue this degree as a pre-established goal was the motivating factor of several of the students, revealing the inherent worth they attributed to the DNP. These students communicated with colleagues about this innovative degree and are affirming its value to the nursing profession and the broader healthcare system. As respected peers, their opinion leadership may influence later adopters in choosing this degree for themselves. These student experiences, as described in this study, may serve to prompt tentative students in their own decision making process.

\section{Professional advancement}


As previously stated, the most prominent theme derived from the student interviews was the desire to increase and enhance one's professional identity. Words describing concepts of respect, dignity, influence, power and responsibility were found throughout the participant's statements and quickly developed this theme as central to their decision to pursue this degree. One interviewee described the DNP degree as “getting attention" and enabled her ability to network within her practice environment: "contacts are important for community support, this degree increases those opportunities.” Another student, discussing her increased capacity to improve nursing practice and patient outcomes, described her identity as a nurse as "an enhanced version when it comes to patient care (as compared to an MD). We may lack the medical knowledge of an MD, but when it comes to compassion, care and critical thinking...I think we have them beat!" Yet again, a nurse described the DNP degree as "fostering my skills in applying EBP for system change in the clinical setting. I feel prepared to be a leader in health care policy".

Students also described professional advancement as increasing their responsibility and ability to serve, whether it was to serve patients at work, students in school, or organizations in their community. Statements, such as "to improve the quality of life for patients within their perception of what wellness means", "to make healthcare more accessible and understandable," to "contribute to the health of others," to "assist churches in preventative type programs," as well as "to educate nurses, patients and families" each express the spirit of selflessness and humanitarianism that characterized students' responses about how this degree would enhance their professional roles. 
Similar to the desire to achieve a goal, the desire to advance professionally was often associated with a new opportunity or position at their job site. One participant stated that she was directly influenced by the directors of her program and stated their input provided "a real push" in her decision to obtain this degree. Many participants aspired to secure a teaching position in a graduate nursing program and viewed this degree as required to do so. While several participants were already part-time faculty, the ability of these clinicians to confirm their teaching role while simultaneously enhancing their clinical skills seemed to be of considerable value. Professional advancement through the DNP degree was not only a process of transitioning from point A to point B; it was additionally portrayed as the opportunity to concurrently enrich the essence of both clinical and teaching roles, or as one student summed it up, the DNP was simply "a better fit."

Increased job skills were also cited as being a result of the DNP curriculum. Skills outlined included "applying EBP for system change in the clinical setting," "more autonomy ordering diagnostic tests and other such things," "developing healthcare policy," and learning "how to influence programs and practice through leadership." These statements attest to the macro nature of the DNP's clinical role and revealed skills that were intended to change "the big picture of the human experience in healthcare."

A final aspect characterizing the theme of professional advancement was the emphasis placed on leadership and the importance of having good nurse leaders representing the profession of nursing within healthcare. Interviewees often stressed how 
the DNP program helped them reflect upon and improve their leadership and management styles, all the while increasing their ability to promote nursing's influence and position. While partially corresponding to personal development, leadership and leadership skills were also fundamental to enhancing their professional roles as either educators and/or clinicians.

\section{Attributes of program}

Another theme identified was attributes of program. The immediate responses to the question inquiring into the students' experiences led to the use of words such as rigorous, stress, exhausting, overwhelming, rewarding, fulfilling, and satisfying to describe the curriculum, workload and program expectations. A student stated candidly that "there are simply not enough hours in the day to complete all the assignments in a timely fashion," this sentiment was shared by most, if not all, participants. She continued stating: "I am still struggling to maintain deadlines in my academic, personal, and professional lives... however I have no regrets and would encourage others to do so." Similarly, another student wrote "it is helpful to stay on task and to take one week at a time... very difficult to catch up once behind." Another participant relayed frustration over "expectations and requirements that far exceeded the normal requirements and time for a three credit course. It would have been easier to swallow if the credits allotted matched the hours invested."

Demonstrating a retrospective and reflective view of her time as a DNP student, a recent graduate, discussing the difficult workload and long hours she experienced, 
offered some advice and hope to current students. She wrote: "Don't underestimate the amount of work doctoral study requires... but enjoy the experience while you can. These days will pass and you'll look back and wish you would have smelled more roses."

While articulating the characteristics of their program, students tended to express the most emotion with regards to the workload. They also discussed their respective learning environments, however, and how they affected their experiences. Topics included the online versus face-to-face formats, the financial cost (which was described as both a contributing and limiting factor), their capstone project, intensives, and the clinical hour requirements. Several students expressed thoughts regarding the content; reporting a heavy emphasis on research, statistics, epidemiology and organizational management. None were disappointed or surprised and all evaluated the content as being enlightening and important to an advanced nurse's education.

The learning format, whether in classroom or online, appeared to be the most significant factor in the decision process when selecting a program. Similar to Montgomery's 2011 findings, the format also seemed to be very influential in shaping the experiences of the individual. Most of the negative experiences described were directly attributed to the format itself, and not to the program or curriculum. Difficulties with online communication, delayed faculty response times, and a sense of detachment with a perceived lack of cohesiveness amongst student groups were identified as some of the challenges experienced by the students, all of which were associated with distance learning. 
The traditional classroom environment was not without challenges though, as one participant, who was the only clinically based student in her class, experienced some conflict with her peers and felt that her input and perspectives were not always heard. This may have occurred due to the majority-rules mentality that is often prevalent in dynamic social groups such as in a classroom, and may not have been as prevalent in an online discussion.

Moreover, whether online or face-to-face, most participants described their program of study as being positive and rewarding, possessing attributes that promoted and sustained "creative" and stimulating" conversations. Sentiment towards each participant's respective program was overall very positive; when asked to describe her experience as a DNP student, one recent graduate exclaimed, "I would describe my experience as absolutely wonderful. I loved the learning and respected the faculty greatly." One student summarized the benefits of small classroom size in her traditional program stating, "My cohort consists of only three APN's... because we are from such different fields, our classroom discussions have been richer." Comments such as "I have really enjoyed the DNP program," "what I truly enjoy about the majority of courses is the amazing dialogue and ideas that emerge from class discussion" and "I wouldn't do anything differently" all illustrate that these participants found their programs rewarding and worthwhile. Another student relayed that a benefit from her DNP program was "meeting students from around the world and gaining insight into APN practice in various countries". Exposure and understanding emerged as sub-themes within this category. Most students described their experiences as increasing their perception and 
appreciation of others, increasing their understanding of nursing issues, and enhancing their overall situational awareness in healthcare. This was best described as "the big picture of the human experience in healthcare."

\section{Relationship with others}

The theme relationship with others encompassed several concepts. Encouragement, support, teamwork, conflict, and communication were all common topics with the participants. While there existed isolated negative experiences with peers and faculty members, the theme most representative of the group was that of encouragement and peer support within the participants' communication networks. Accounts of both peer and faculty support were present in approximately a 2:1 frequency ratio and both were reported to have played a major role in the success of each student. "Peer support is critical!" exclaimed one student. Another wrote: "any peer can be a true support system, especially if you migrate toward the right ones. They can help you hangin when you want to throw in the towel. It's great to know you're not alone!" Finally, one participant addressed student and faculty support directly with this statement:

Faculty Support: I received immense support while pursuing my degree... I felt the support from fellow students in the program was excellent, as well as the support from the DNP faculty and my DNP chair while I was working on my project.

Several students reported specific people who were reassuring and others spoke of comfort in group support, knowing that their peers were either co-workers or 
geographically near; "fortunate not to feel isolated because three other faculty members enrolled in program. Also another student is from Rhode Island, one from Massachusetts and one other from Connecticut." The idea of enrolling as a cohort for increased support was present in the responses of four of the seven participants, with one student deliberately choosing her program of study knowing she was enrolling with a peer: "One motivator was that I would be enrolled in a program with a colleague. Knowing that we would be able to assist each other in the academic process influenced my decision." The idea of a mutually shared experience as a motivating factor in the decision to enroll seemingly contradicts the results reported in Resop-Reilly and Fitzpatrick's 2009 study. They found a lack of difference between perceived level of stress and sense of belonging when comparing the scores of DNP students who enrolled as a cohort, individually or with at least one friend or colleague. The findings of this study suggest that the shared and supportive environment played a significant role in reducing student stress.

A shared experience and the development of relationships are two beneficial outcomes for the students in this study. A supportive environment affirmed and encouraged the individuals as they lived through this experience and led to the formation of a small network of nurse leaders who, through their relationships and the sharing of ideas and attitudes, now describe themselves as empowered agents of change, spreading knowledge about the DNP and its role in healthcare. As mentioned in the discussion of the diffusion of innovations theory (Rogers, 2003), innovations are evaluated and adopted by others most often due to word of mouth; personal communications about subjective experiences. These nurses, as members of a graduating group of students, have the 
potential to be champions of this degree by sharing their experiences with others, as well as the reasons they chose to adopt this innovation. Furthermore, as nurse leaders they may describe the content of the curriculum of their program, the benefits and challenges of the DNP role, and explain the future implications for professional nursing to others considering this advanced practice role.

Family support was also included in this theme. One student, discussing her husband's encouragement during her studies, exclaimed: “A marriage must be solid though! lol I give credit to my husband-- could not have completed anything without his support!". Later in the conversation, she continued to tell of the support she was receiving:

Friends and family have brought over food, sent cards and flowers, and many hugs and verbal encouragement. My church family is especially supportive-weekly they give hugs and encouragement. I share (usually through Facebook) the ups and downs--trying to always focus on the positive.

Other areas of support included flexible scheduling at a person's place of employment. This was described as instrumental when students were provided with the required time off to attend intensives, conferences, or other education related activities.

The theme relationship with others was selected to represent the various levels of human interaction that were found in this study. As stated, while most of the peer and faculty interactions were positive, there did remain several accounts where relationships 
were not supportive or beneficial to the students, and this data set deserves equal representation.

One individual described some stress with "your occasional type-A individual" and another recounted frustration with a faculty member who gave little, if any feedback. As mentioned previously, one student found that there existed a difference in perspective between herself and her peers. She wrote:

"The challenge is that I am the only hands on clinician in many of my classes, which can be difficult because I view healthcare through the lens of a provider not a professor.... I am not working on a theory, I am not practicing in a classroom.... am providing care."

When asked if she felt her input was respected she responded:

I think at times my input is not always heard simply because some individuals who are in academia only (and pursuing the DNP) are so far removed from the clinical experience that they cannot relate. It is one thing to teach students to identify signs and symptoms of cardiac arrest, it is an entirely different matter to intervene with an actual patient who has become unresponsive.

Even so, this student described her relationships as mainly positive, continuing to write that she felt supported and had met some amazing nurses whose stories resonated with her and kept her going towards the goal of graduation. 
When asked about the group dynamics during online discussion boards, the interviewees had mixed responses. Some felt that the discussions encouraged individual contributions, while others felt detached and that the group lacked cohesiveness. There were also neutral comments made about peers, likely signifying that students were merely acquaintances and had not chosen to pursue any ongoing friendship with each other. In either case, relationships, whether positive, negative, with self or others, appeared to be the most meaningful and memorable characteristic of student experiences expressed by this cohort of DNP students.

An essential aspect of the theme relationship with others was the natural complexity of each individual person. Relationships based on the idiosyncratic qualities, personality types, and communication styles of students and faculty undoubtedly had significant impact in shaping experiences during this process. Through these relationships they appeared to develop greater mindfulness of others and personal selfawareness. Self-examination and reflection were present in the conversations. Concepts such as self-identity, self-esteem, and increased insight into one's social identity were revealed. Subsequently, another sub-theme was recognized: social identity. This subtheme synthesized both the self-identity and social identity concepts within the participants' responses. They shared objective reflections of how this process has improved their social status, self-esteem, and deepened their situational and societal awareness. Students' comments suggested that, whether in areas of opinion leadership, professional hierarchy or job security, this educational process and degree provided them 
with a tangible source of pride and provided each of them a position of stature within their peer group.

Along with the concepts of relationships and self-identity, the phenomena of social identity and self-categorization subtly arose in three themes: relationship with others, personal development and professional advancement. Identifying how the individual was defined by group membership and how the social cognitive processes associated with group membership affected the identity of the students could provide a basis for future organizational or social psychology research as applied to nursing groups.

The process of self-categorization and the concept of social identity are both ubiquitous in Rogers' theory. By grouping individuals into adopter groups, Rogers identified the social structures that exist among individuals involved in innovationdecision processes and ultimately, which groups adopt the innovation and why. The data and results of this study correlate with several of Rogers' generalizations of the early adopter group, of which most of these participants proved to belong. Two such generalizations include:

- Generalization 7.5: earlier adopters have higher social status than do later adopters (p. 288).

- Generalization 7.6: earlier adopters have a greater degree of upward social mobility than do later adopters (p. 288). 
Rogers continued to describe personal characteristics of earlier adopters: greater empathy towards others, have more open mindedness, have a greater ability to deal with abstractions and more rationality than later adopters (generalizations 7-8, 7-9, 7-10, 7-11, p. 289), all of which appeared in the conversations and are reported as results within this study. Communication styles of the participants also reflected the behaviors of early adopters, including increased social participation, more contacts with innovators, and more actively seeking out information from others (gen. 7.18 - 7.26, pp. 290-291). These characteristics may serve to differentiate the group of individuals who engaged with the researcher from those who responded with interest yet declined to actively participate. Finally, the engaged participants also exhibited qualities of the earlier adopter group, having "high aspirations in regards to formal education, higher status, occupations and so on" (p. 290). The results of this study and the characteristics of the individuals interviewed gained meaning when viewed through the lens of Rogers' theory.

The findings of this study add to the body of knowledge surrounding the experiences of students when pursuing a doctorate of nursing practice and the results are both validated and confirmed by other research findings. The themes of this study echo Baldwin's 2013 core concepts and mirror her deduced theory of “desire to enhance professional and personal identity, while being faced with numerous challenges" (p. 481). Themes from her study, perception of others, personal development, professional development/career opportunities, challenges and coping mechanisms correspond with themes deduced from the data collected for this study. Tabled below are examples of similar concepts and themes of each study. 


\begin{tabular}{|c|c|}
\hline $\begin{array}{l}\text { Key conceptual labels, Baldwin } 2013 \\
n=5\end{array}$ & $\begin{array}{l}\text { Synthesized statements, Neilson } 2014 \\
\mathrm{n}=7\end{array}$ \\
\hline Admiration, respect and prestige & Being prepared to be a leader \\
\hline Balancing work/personal life/academic & Demonstrating commitment to nursing \\
\hline course & Increasing critical thinking \\
\hline Be taken seriously by others & Increasing comfort and confidence levels \\
\hline Desire to learn more & Increasing opportunities \\
\hline Family and social commitments & Increasing personal power \\
\hline Higher clinical positions & Increasing recognition and respect \\
\hline Impress others & Mastering a higher skill level \\
\hline Leadership skills & Personal sacrifices \\
\hline Personal achievement & Securing a more desirable role \\
\hline Pride in achievements & Strengthening personal identity \\
\hline Professional confidence & Struggling to meet deadlines \\
\hline Self-development & \\
\hline Support & \\
\hline Time pressures & \\
\hline Widen profile & \\
\hline Baldwin Categories & Neilson Themes \\
\hline Professional development/career & Professional advancement \\
\hline Personal development & Personal development \\
\hline Perception of others & Relationships with others \\
\hline Opportunities & Program attributes \\
\hline
\end{tabular}


Challenges

Coping mechanisms
Achieving personals goal

This study also found that participants expressed a great deal of respect and admiration for this degree, upholding Baldwin's claim that DNP students share high levels of pride in their achievement and view this degree as a worthy and valuable goal. The results of this study would therefore argue against the suggestion that the practice doctorate is perceived as inferior or "second class" to the $\mathrm{PhD}$ (Ellis, 2007, p. 2276).

Differences existed between the current study and Baldwin's research in two areas: the emphasis on interpersonal relationships and the participant's critique of their respective programs of study. In the latter, discussions appeared centered on what factors facilitated or hindered learning in their respective academic environments and how the program format affected their experiences. This did not appear to be a prominent topic of discussion in Baldwin's study. Perhaps this was due to the fact that the participants in that study were all in the same DNP program as opposed to the diverse learning environments represented in this study (traditional classroom, fully online and hybrid programs). While the concept of relationships was found in Baldwin's article, it did not lead to a focused discussion.

Similarities between this study and Baldwin's, which was conducted in the UK, invite future comparisons between American and British cohorts. Further research is indicated in other cultural settings. 
The idea of "fit," as described in Halter, Kleiner \& Hess (2005), was also evident in the participants' responses in this study, as the personal preference for either online or traditional environments influenced individual decision making processes. Two of the three concepts described by Halter, Kleiner \& Hess, liking the fit and making it fit, were both present in several student statements: "I researched the program of study beforehand and had some understanding of what the course work would be like before I began the program... The program has met and exceeded my expectations", as well as a student who clearly stated "the DNP fit for me. I am not a huge research method person and have been more clinically based. I figured a capstone project fit my goals." Finally, this notion of fit was also reflected in another student's statement: the "capstone project fit better and can be implemented ... online program was a better fit for me, don't have time to sit in classes."

Another area of comparison existed between this study and the phenomenological study reported in 2013 by Arvidsson and Franke that described the experiences of nurse clinicians as they transitioned into nurse researchers during their $\mathrm{PhD}$ education. Similarities found between these two groups of study participants were that they both felt more prepared to be nurse leaders, to take professional action and to problem solve issues in the nursing profession. This comparison would substantiate that both degrees adequately educate and create advance practice nurses in their respective specialties. 


\section{Summary and Conclusions}

\section{Summary}

This qualitative study was intended to describe and characterize DNP student experiences and to identify the factors that contributed to their decision to pursue this degree. An extensive literature review was conducted using online databases. Topics reviewed included the historical development of doctoral education in nursing, nursing practice doctorates, and student experiences in doctoral nursing programs. A gap in the literature was identified in the areas of student experiences in nursing practice doctoral programs and the reasons why current advanced practice nurses choose to obtain this degree. Rogers' theory of diffusion of innovations (2003) was selected to guide the study as, although practice doctorates are not a new concept, the DNP itself remains a relatively new innovation. Rogers' theory delineates how innovations spread among individuals over time and identifies the factors that contribute to their eventual adoption or rejection.

After obtaining IRB approval, a cohort of DNP students was selected using a snowball recruitment method and subsequent email interviews were carried out over several weeks. Interviews began by asking two questions, a) what factors contributed to your decision to pursue this degree, and b) tell me about your experiences as a DNP student. Confidentiality and data security were maintained at all times and no personal or significant demographic information was solicited.

Seven students participated in the interview process and conversations lasted as

long as the participants continued responding or until the pre-established end date of 
January $20^{\text {th }}, 2014$. Data were organized and coded by question and individual participant. Concise, representative phrases were extracted from the conversations, tabled, and synthesized with similarly coded responses. From this synthesized data set, themes were extrapolated and cross-examined for validity and accuracy by another researcher.

Five major themes were established from the data:

- Personal development: This theme was common to all participants. Personal growth and development was evidenced by multiple statements reflecting a personal evolution during this process; growth in areas of confidence, knowledge, and insight into global health-related challenges.

- Achieving personal goal: The desire to pursue and accomplish a personal goal was conveyed through many of the participants' statements. This goal was either the DNP degree itself or a goal directly facilitated by the degree, such as a new job opportunity, self-fulfillment via a terminal degree, or simply an altruistic desire to effect change within the healthcare system.

- Professional advancement: The most overt theme was that of professional advancement. Whether it was directly tied to a promotion within the workplace, an opportunity in the community or to enable teaching at the graduate level, most participants were clear that this degree would directly affect their careers in a positive way. Other benefits included a more distinguished professional identity, 
broadening one's influence amongst peers and demanding more respect at the workplace.

- Program attibutes: This theme centered on the characteristics and structures of their respective programs and the challenges and facilitators that existed in their learning environment. The concepts of time management, communication with faculty, distance versus class learning, amount of work expected and other program specific issues formed this group of data.

- Relationship with others: Participants also discussed the concept of relating with other individuals and the ability to garner support from peers, family and friends. Relationships served as the primary source of support for the DNP students. The mutuality formed during shared experiences was described as mostly positive, but several participants also related some negative experiences in the form of conflict with their peers and communication challenges with faculty members.

\section{Conclusions}

APRNs have traditionally had a strong presence in community and rural healthcare delivery. Discussing the DNP role and identifying the positive experiences of students in DNP programs may indirectly affect these areas of great need by encouraging the recruitment of new APRNs into these leadership roles, as well as reinforcing the role of advanced practice nurses in the care of underserved populations. DNP graduates, with improved abilities to lead change, develop and implement healthcare programs along 
with being actively involved in the management and delivery of care, may be able to positively affect the current disparities in outcomes that exist in vulnerable populations.

Another conclusion identified was the benefit of being a team leader. This additional education refined the APRNs communication skills along with their ability to act as not only members, but as genuine leaders within the interdisciplinary healthcare teams. Leadership skills appeared as a reoccurring theme in the conversations with the participants and the transition from being a team member to a team leader was identified in several conversations. The DNP preparation enabled these APRNs to have a greater skill-set and level of confidence in being team leaders, improved their leadership styles and made them into more effective agents of change in their workplace.

Another significant conclusion of this study was found in the students' reflections of how this learning experience matured them as individuals. An increased level of knowledge and wisdom characterized their personal and professional journeys and led to a deeper understanding of the ethical care, cultural competence and social responsibility that was now essential to their APRN practice.

This research increased the knowledge of DNP student experiences and provided insight into why these APRNs decided to pursue this degree. These participants, having shared their stories, have enhanced the understanding of this process and shown it to be a valuable and worthy goal. This information may be helpful in assisting others considering this degree as well as nurse leaders in developing new DNP programs of study. 


\section{Limitations}

As snowballing was the primary recruitment strategy, there may have existed a local bias due to a decreased geographical scope. Unknown to the researcher, respondants may have reflected cultural biases inherent to their specific DNP programs. Student experiences may have also reflected normal challenges found in newly developed programs of study that may not be characteristric of more traditional, well-establised programs. Faculty support of, or antagonism to the DNP degree may also have shaped the experiences of the students as there exists a wide range of adoption within this population. In addition, the timing of the data collection period, which was over the holiday season, potentially created inconsistencies in response times and likely contributed to the overall low response rate. Of the fourteen individuals that contacted the researcher expressing a desire to participate, only half of these students acutally did; seven either never returned a signed consent or did not respond to the questions after having done so.

Additionally, a significant limitation was the challenge that email presented in creating truly engaging conversations between individuals. Although limitations and challenges to this format were recognized in the development of the process and actively confronted during the process, they were not entirely mitigated. The inability to obtain spontaneous and impulsive responses, enhanced with corresponding body language or

other non-verbal forms of communication, possibly limited the richness of the data 
obtained. On the other hand, being able to respond during their own time frame and without judgement may have enabled respondents to be more open in their responses.

E-mail responses tended to be targeted to the questions asked, brief and direct in nature. Although remaining thoughtful and complete within their scope, they lacked tangential comments that may have occured in face-to-face interviews. Most notably was the lack of fluidity and ensuing richness that are normally present in face-to-face dialogue. While the e-mail format allowed for accurate responses to the solicited queries, it may have reduced the dialogue and return questioning by the respondents. Due to the direct and brief nature of the responses, the subsequent conversations felt interviewer-led. The richness and quality of data gathered was directly dependent on the interviewer's ability to ask the right question at the right time, and became the limiting factor in the data that was gathered.

\section{Facilitators}

There were two major facilitators within this study. First was the enthusiasm with which the APRNs pursuing the DNP discussed their educational process, career goals, and surrounding issues. Participants wanted to discuss their experiences with this innovative educational pathway to nursing excellence. Many expressed pride in their accomplishments, as manifested in their willingness to share their stories. Interestingly, the participants themselves became facilitators, in that they provided a significant source of personal encouragement and motivation to the researcher during this process. 
A second aspect that facilitated this study was the overall high computer literacy and familiarity with online communication amongst this cohort of post-graduate students and their ease with email correspondence. The process of communication and data collection was not a barrier to receiving their comments. 


\section{Recommendations and Implications for Practice}

Recommendations exist in the following areas:

a) Future research is needed to identify why DNP graduates choose this degree instead of the traditional PhD as their entrance into academic settings. The majority of these participants stated they pursued this degree to increase their opportunities within teaching universities and preferred this degree over the $\mathrm{PhD}$. Few of these APRNs perceived this degree as essential to their clinical practices or to the advancement of their clinical careers. A more comprehensive, national survey into what DNP graduates do with this degree, and why, is warranted. Intestingly, in contrast, Lee's 2009 study recommended that faculty pursue practice doctorates in order to provide greater diversity within practice doctorate programs and to better meet student needs.

b) There is a need to further identify and clarify the role of the DNP within the healthcare system. An objective and evidenced-based review of DNP educated APRNs clinical performance and outcome evaluation is warranted to substantiate and validate the contributions made by these terminal degree professionals.

c) Future research into how faculty and program directors of online nursing programs may use innovative technologies to effectively educate students, while enabling a supportive environement where relationships are strengthened, and where an increasing sense of belonging and camaraderie may be promoted among students. 
Similar recommendations existed in previous studies examining student experiences (Resop Reilly \& Fitzpatrick (2009).

Implications of this study exist for the individual nurse contemplating the DNP degree. Findings support the importance of students selecting the right learning platform for their program. Each potential student should conduct an examination of individual learning styles, personal preferences and time commitments before selecting the learning environment that will optimize their experience and the likelihood of success. Study findings also highlight the significant impact that relationships can have on a student's experience. Students who actively participated in team building, class activities and discussions reported that they fared better than those who remained isolative, showing less signs of depression and isolation.

Program directors who want to recruit APRNs into their DNP educational program can also benefit from these study results. The experiences and challenges reported by students in this study can provide direction to the development of a positive and supporting learning environment. Factors that contributed to the students' decision to pursue this degree may also be useful in marketing the DNP program. Conversely, reported negative experiences may suggest areas of program improvement that would mitigate their occurrence.

These students are early adopters of the DNP education movement. Faculty and administrators can utilize this information to better understand the dynamics of adoption that existed among this group of APRNs and can tailor their programs to meet the needs 
of current and future students. As described in the theory of diffusion of innovations (Rogers, 2003), the needs and characteristics of the various groups of adopters are different and a strategy implemented with one group may not be effective with another. The recruitment and retention strategies, along with the structure of the learning environment, should be designed specifically to optimize the experiences of the next generation of DNP students.

Finally, implications exist for the profession. As this process evolves, nurses have the opportunity to demonstrate to other professions involved in healthcare that nursing has the ability to adapt to change, be flexible and to continue being leaders in the delivery of care. After all, one of the greatest strengths of the nursing profession has been its ability to remain versatile, relevant and competent in the provision of health care services to patients. 


\section{References}

American Association of Colleges of Nursing (2004). Position statement on the doctorate of nursing practice. Available at http://www.aacn.nche.edu/dnp/positionstatement.

American Association of Colleges of Nursing (2006). The Essentials of Doctoral Education for Advanced Nursing Practice. Available at http://www.aacn.nche.edu/publications/position/DNPEssentials.pdf.

American Association of Colleges of Nursing (2014). The DNP fact sheet. Available at http://www.aacn.nche.edu/media-relations/fact-sheets/dnp.

American Association of Nurse Anesthetists (2007). Position on doctoral preparation for nurse anesthetists. Retrieved from http://www.aana.com/ceandeducation/educational resources/ Documents/AANA_Position_DTF_June_2007.pdf.

American Association of Nurse Practitioners (2013). Discussion paper: Doctor of nursing practice. Available at http://www.aanp.org/images/documents/publications/doctorofnursingpractice.pdf

American College of Nurse-Midwives (2010). ACNM response to ANA position statement on the DNP. 2010. Retrieved from http://www.midwife.org/documents/ACNMonDNP.pdf. 
American Nurses Association, (2011). The doctorate of nursing practice: advancing the nursing profession. Revised position statement, available online at http://ana.nursingworld.org/drpractice.

American Nurses Association (2013). Nursing Education. Available at http://nursingworld.org/MainMenuCategories/Policy-Advocacy/State/LegislationAgenda-Reports/NursingEducation.

Apold, S. (2008). The doctor of nursing practice: looking back, moving forward. Journal for nurse practitioners 4(2), 101-108. Retrieved from http://www.medscape.com/viewarticle/571070.

APRN Joint Dialogue Group Report. (2008) Consensus model for APRN regulation: licensure, accreditation, certification \& education. Consensus Work Group \& the National Council of State Boards of Nursing APRN Advisory Committee. Available at: https://www.ncsbn.org/7_23_08_Consensue_APRN_Final.pdf.

Arviddson, B., Franke, A. (2013). Nurses' various ways of conceiving their learning process as doctoral students: a phenomenographic study. Nurse Education in Practice, 13, 53-57.doi.org/10.1016/j.nepr.2012.07.002. Retrieved from http://www.sciencedirect.com/science/article/pii/S1471595312001333\#.

Baldwin, S. (2013). Exploring the experiences of nurses studying professional doctorates. British Journal of Nursing, 22(8), 476-483. Retrieved from http://EBSCOHost.com. 
Beckstead, J. (2010). DNP=PhD-light, or old wine in new bottles? International journal of nursing studies. 47(6), 663-664. doi:10.1016/j.ijnurstu.2010.02.008

Bellini, S., Cusson, R., M. (2012). The doctor of nursing practice for entry into advanced practice: the controversy continues as 2015 looms. Newborn and infancy nursing reviews 12(1), 12-16. doi:10.1053/j.nainr.2011.12.008

Bourner. T., Bowden, R., Laing, S. (2001) Professional Doctorates in England. Studies in Higher Education, 26(1): 65-83. doi:10.1080/03075070124819

Brown-Benedict, D. J. (2008). The doctor of nursing practice degree: lessons from the history of the professional doctorate in other health disciplines. Journal of Nursing Education, 47(10), 448-457. Retrieved from http://www.doctorsofnursingpractice.org/cmsAdmin/uploads/BrownBenedict2008.pdf.

Brown, M. A., Kaplan, L. (2011). Faculty perspectives of the DNP; a study of advocacy, ambivalence, antagonism. The nurse practitioner 36(4), 36-44. doi.10.1097/01.NPR.0000394725.20441.25

Burman, M. E., Hart, A. M., McCabe, S. M. (2005). Doctor of nursing practice: Opportunity amidst chaos. American journal of critical care, 14(6), 463-464. Retrieved from http://www.doctorsofnursingpractice.org/cmsAdmin/uploads/Burman2005.pdf. 
Carlson, L. H. (2003). The clinical doctorate - asset or albatross? Journal of Pediatric Health Care, 17(4), 216-218. Retrieved from http://www.doctorsofnursingpractice.org/cmsAdmin/uploads/Carlson2003.pdf.

Carter, M. (2013) The evolution of doctoral education in nursing. In S. DeNisco and A. Barker. (Eds.), Advance practice nursing, evolving roles for the transformation of the profession (2 ed.), (ch. 3). Burlington MA : Jones and Bartlett.

Chase, S. K., Pruitt, R. H. (2006). The practice doctorate: Innovation or disruption? Journal of Nursing Education, 45, 155-161.

Christman, L. (1980). Leadership in practice. Journal of Nursing Scholarship, 12, 31-33.

Clinton, P., Sperhac, A. M., (2006). National agenda for advanced practice nursing: The practice doctorate. Journal of professional nursing, 22(1), 7-14. Retrieved from http://www.doctorsofnursingpractice.org/cmsAdmin/uploads/ClintonP2006. pdf.

Cope, D. G. (2014). Methods and meanings: credibility and trustworthiness of qualitative research. Oncology nursing forum 41:1, (89-94). doi 10.1188/14.ONF.89-91

Cronenwett, L., Dracup, K., Grey, M., McCauley, L., Meleis, A., Salmon, M. (2011). The doctor of nursing practice: a national workforce perspective. Nurse outlook 59, 917. doi:10.1016/j.outlook.2010.11.003 
Dennison, R. D., Payne, C., Farrell, K. (2012). The doctorate in nursing practice: moving advance practice nursing even closer to excellence. Nursing clinics of north America 47, 225-240. doi:10.1016/j.cnur.2012.04.001

Dracup, K., Bryan-Brown, W. (2005). Doctor of nursing practice - MRI or total body scan? American journal or critical care 14 (4) 278-281. Retrieved from http://www.ncbi.nlm.nih.gov/pubmed/15980416

Dracup, K., Cronenwett, L., Meleis, A. L., Benner, P. E. (2005). Reflections on the doctorate of nursing practice. Nursing outlook 53, 177-182. doi:10.1016/j.outlook.2005.06.003

Edwardson, S. R. (2010). Doctor of philosophy and doctor of nursing practice and complementary degrees. Journal of professional nursing 26(3) 137-140. doi:10.1016/j.profnurs.2009.08.004

Ellis, L. (2005). Professional doctorates for nurses: mapping provision and perceptions. Journal of advanced nursing, 50(4), 440-448.Retrieved from http://doctorsofnursingpractice.org/cmsAdmin/uploads/Ellis2005.pdf.

Ellis, L. (2007). Academics' perceptions of the professional or clinical doctorate: findings of a national survey. Journal of clinical nursing 16(12): 2272-2279. doi:10.1111/j.1365-2702.2007.02120.x

Evans, C., Stevenson, K. (2009). The learning experiences of international doctoral students with particular reference to nursing students: A literature review. 
International journal of nursing studies 47, 239-250.

doi:10.1016/j.ijnurstu.2009.05.025

Fitzpatrick, J. J. (1989). The professional doctorate as an entry level into clinical practice. Perspectives in nursing, 1987-1989, (pp. 53-56). New York: National League for Nursing. Retrieved from http://www.nln.org.

Flaherty, M. J. (1989). The doctor of nursing science degree: evolutionary and societal perspectives. In S. E. Hart (Ed.), Doctoral education in nursing: History, process, and outcome. (pp. 17-31). New York: National League for Nursing.

Fulton, J. S., Lyon, B. L. (2005). The need for some sense making: Doctor of nursing practice. Online Journal of Issues in Nursing, 10 (3). Retrieved from http://www.nursingworld.org/MainMenuCategories/ANAMarketplace/ANAPerio dicals/ OJIN/TableofContents/Volume102005/No3Sept05/tpc28_316027.aspx.

Grace, H.K. (1989). Issues in doctoral education in nursing. Journal of Professional Nursing, 5(5), 266-270. doi.org/10.1016/8755-7223(89)90037-9

Grey, M. (2013). The doctor of nursing practice: defining the next steps. Journal of nursing education, 52(8), 462-465. doi: 10.3928/01484834-20130719-02

Hader, R. (2011). Education Matters. Nursing management, 42(7), 22-27. doi:10.1097/01.NUMA.0000398920.55764.73 
Halter, M. J., Kleiner, C., Hess, R. F. (2005). The experiences of nursing students in an online doctoral program in nursing: A phenomenological study. International journal of nursing studies 43, 99-105. doi:10.1016/j.ijnurstu.2005.03.001

Hathaway D., Jacob S., Stegbauer C., Thompson C., Graff C. (2006). The practice doctorate: perspectives of early adopters. Journal of nursing education, 45(12), 487-496. Retrieved from http://www.doctorsofnursingpractice.org/cms Admin/ uploads /Hathaway_Jacob2006.pdf.

Holloway, I., Wheeler, S. (2010). Qualitative research in nursing and healthcare ( ${ }^{\text {rd }}$ ed). Wiley- Blackwell: New Jersey.

History of baccalaureate nursing education and entry into practice. (May, 2013). Available at www.nursingeducationhistory.org.

Institute of Medicine (2010). The future of nursing: leading change, advancing health. Available at http://www.iom.edu/Reports/2010/The-future-of-nursing-leadingchange-advancing-health.aspx.

Instone, S. L., Palmer, D. M. (2013). Bringing the Institute of Medicine's report to life: developing a doctor of nursing practice orthopedic residency. Journal of nursing education 52(2), 116-119. doi: 10.3928/01484834-20130121-03

Ketefian S., Neves E., Gutiérrez M. (2001). Nursing doctoral education in the Americas. Online Journal of Issues in Nursing 6(2). Available at www.nursingworld.org//MainMenuCategories/ANAMarketplace/ANAPeriodicals 
/OJIN/ TableofContentsVolume62001/No2May01/ArticlePrevious

Topic/DoctoralEducation Americas.aspx.

Kirshling, J. (2013). Designing DNP programs to meet required competencies context for the conversation. Presentation at the 2013 Doctoral Education Conference. Available at http://www.aacn.nche.edu/dnp/JK-2013-DNP.pdf.

Lee, N. J. (2009). Professional doctorate supervision: exploring student and supervisor experiences. Nurse education today 29, 641-648. doi:10.1016/j.nedt.2009.02.004.

Lenz, E. R. (2005). The practice doctorate in nursing: an idea whose time has come. Online Journal of Issues in Nursing, 10 (3) 16 p. Retrieved from www.pubmed.com.

Lewis, M. (2011). The doctor of nursing practice: a sentiment and credential correlation. Unpublished dissertation. Available at http://www.crna.tcu.edu/docs/dnpa\%20capstone/Lewis $\% 20$ M.The $\% 20$ Doctor $\% 20$ of $\% 20$ Nursing $\% 20$ Practice $\% 20 \mathrm{~A}$ $\% 20$ Se ntiment $\% 20$ Analysis\%20and\%20Credential\%20Correlation\%20.pdf.

Lewis, M., Welliver, M., \& Leach, S. (2012). The doctor of nursing practice: a sentiment analysis and credential correlation. International journal of advanced nursing studies, 1(1), 43-57. Retrieved from http://www.sciencepubco.com/index.php/IJANS/article/view/39/168.

Lincoln, Y.S., Guba, E.G. (1985). Naturalistic inquiry. Newbury Park, CA: Sage. 
Mateo, M. A., Kirchhoff, K. T. (2009). Research for advanced practice nurses; from evidence to practice. Springer: New York, NY.

Marion, L., Viens, D., O'Sullivan, A. L., Crabtree, K., Fontana, S., \& Price, M. M. (2003). The practice doctorate in nursing: Future or fringe? , Topics in Advanced Practice Nursing eJournal, 3(2). Retrieved from http://www.medscape.com/viewarticle/453247.

McEwen, M., Bechtel, G., A. (2000). Characteristics of nursing doctoral programs in the United States. Journal of professional nursing, 16 (5), 282-292. doi:10.1053/jpnu.2000.9458

McLoughlin, K. A., (2006). Consider this... the DNP (doctor of nursing practice). Archives of psychiatric nursing, 20(5), 245. Retrieved from http://www.doctorofnursingpractice.org/cmsAdmin/uploads/McLoughlin2006pdf.

Meleis, A. I., Dracup, K. (2005). The case against the DNP: history, timing, substance, and marginalization. Online Journal of Issues in Nursing 10, 3. Retrieved from www.EBSCOHost.com.

Montgomery, K., L. (2011). Leadership redefined, educating the doctorate of nursing practice nurse leader through innovation. Nursing administration quarterly, 35(3), 248-251. doi: 10.1097/NAQ.0b013e3181ff38bc 
Mundinger, M., Kane, R., Lenz, E., Totten, A. M., Tsai, W.Y., Cleary, P. D., et al. (2000). Primary care outcomes in patients treated by nurse practitioners or physicians: A randomized trial. JAMA, 28(1), 59-61.

Mundinger, M., O. (2005). Who's who in nursing: bringing clarity to the doctor of nursing practice. Nursing outlook, 53(4), 173-6. Retrieved from www.Pubmed.org.

National Association of Clinical Nurse Specialists. (2009). Position Statement on the Nursing Practice Doctorate. Available at http://www.nacns.org/docs/PositionOnNursingPracticeDoctorate.pdf.

Newman, M.A. (1975). The professional doctorate in nursing: A position paper. Nursing Outlook, 23 (11) $704-704$.

Nurse Practitioner Roundtable (June, 2008). Nurse Practitioner DNP Education, Certification and Titling: A Unified Statement. Retrieved from http://www.nonpf.com/associations/10789/files/DNPUnifiedStatement0608.pdf.

Olshansky, E. (2004). Are nurses at the table? A new nursing degree could help. [Editorial] Journal of professional nursing, 20(4), 211-212. Retrieved from http://www.doctorsofnursingpractice.org/cmsAdmin/uploads/Olshansky2004.pdf.

Opdennaker, R. (2006). Advantages and disadvantages of four interview techniques in qualitative research. Forum:qualitative social research 7(4). Available at http://www.qualitative-research.net/index.php/fqs/article/view/175/391\#g23. 
O'Sullivan, A. L., Carter, M.,Marion, L., Pohl, J. M. \& Werner, K. E. (2005). Moving forward together: the practice doctorate in nursing. Online Journal of Issues in Nursing. 10 (3) 99-113. Retrieved from www.EBSCOHost.com.

Partin, B. (2005). The DNP; a natural evolution. The nurse practitioner. 30 (11) 23-24. Retrieved from www.pubmed.org.

Pearson, A., Borbasi, S., and Gott, M., (1997). Doctoral education in nursing for practitioner knowledge and for academic knowledge: The University of Adelaide, Australia. Journal of Nursing Scholarship, 29(4), 365-368. Retrieved from http://www.doctorsofnursingpractice.org/cmAdmin/upload /PearsonBorbasiGott1997.pdf.

Posmontier, B., Breiter, D., Cartier, J., Dilks, S. S., Esposito, N., Handrup, C., ... Newton, M. (2013). ISPN DNP task force statement on the DNP. American psychiatric nursing 27 (1), 56-60. doi.org/10.1016/j.apnu.2012.12.002

Resop Reilley, J. E., Fitzpatrick, J. J. (2009). Perceived stress and sense of belonging in doctor of nursing practice students. Journal of professional nursing, 25(2), 81-86. doi:10.1016/j.profnurs.2008.10.002

Roberts, M. J., Miller, K., P. (2009). Should master's NP programs be replaced by DNP programs? Point; counterpoint. The journal for nurse practitioners. March Ed. doi:10.1016/j.nurpra.2008.12.019 
Robinson, L. (2009). A summary of diffusion of innovations. (graph). Available at http://www.enablingchange.com.au/Summary_Diffusion_Theory.pdf.

Rogers, E. M. (2003). Diffusion of innovations. ( $5^{\text {th }}$ ed.). Free Press : New York, NY.

Rogers, M. E. (1966). Doctoral education in nursing. Nursing forum 5(2) 75-82. doi: 10.1111/j.1744-6198.1966.tb00336.x

Rowberg, M. (2005). Evaluating the doctorate of nursing practice. Why have a doctorate of nursing practice? The journal for nurse practitioners, 1, 212-215. Retrieved from http://www.doctorsofnursingpractice.org/cmsAdmin/uploads/ Rowberg2006.pdf.

Schlotfeldt, R. M. (1978). The professional doctorate: Rationale and characteristics. Nursing Outlook, 26: 302-311.

Shelby, S. (2008). The development of a standardized dermatology residency program for the clinical doctorate in advanced nursing. Dermatological nursing 20(6) 437447. Retrieved from www.pubmed.org.

Smith, D. C. (2006). Is the burden worth the benefit of the doctorate of nursing practice (DNP) for NPs? Doctorate of nursing practice: the time is now. Nephrology nursing journal. 33(6), 685-687. Available at http://www.ncbi.nlm.nih.gov/pubmed/17219731. 
Vesser, P. I., Stegbauer, C. C., Russell, C. K. (1999). Developing a clinical doctorate to prepare nursed for advance practice at the University of Tennessee, Memphis. Journal of nursing scholarship, 31(1), 39-41. Doi:10.1111/j.15475069.1999.tb00418.x

Wall, B. M., Novak, J. C., Wilkerson, S. A. (2005). Doctor of nursing practice program development: reengineering health care. Journal of nursing education 44(9), 396403. Retrieved from www.pubmed.org. 